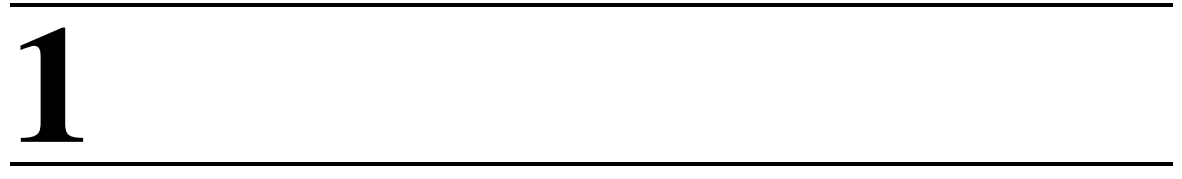

\title{
THEORETICAL MODELING OF RADIATION-INDUCED DNA DAMAGE
}

\author{
Anil Kumar and Michael D. Sevilla \\ Department of Chemistry, Oakland University, Rochester, MI 48309, USA
}

\subsection{INTRODUCTION}

Ionizing radiation causes a variety of damages to DNA in living systems. Thus, the understanding of radiation-induced chemical processes leading to specific damage in DNA is of substantial biological importance ${ }^{1-10}$ Radiation ionizes each component of DNA (i.e., base, sugar, phosphate) and the surrounding water molecules in a random fashion and produces a cascade of secondary electrons, most of which are below $15 \mathrm{eV}$ and are designated as low-energy electrons (LEE). LEE are produced in a large quantity $\left(4 \times 10^{4} \text { per } \mathrm{MeV} \text { energy deposited }\right)^{11}$ along the tracks of the ionizing radiation and have been shown to result in direct DNA damage in model systems in the seminal work of Sanche and co-workers, who found that LEEs create single- and double-strand breaks (SSBs and DSBs) in DNA through dissociative electron attachment (DEA). ${ }^{12-18}$ These findings having been substantiated by the work of others. ${ }^{19-22}$ Only a small fraction of LEE result in DNA damage, because most electrons are thermalized and either recombine with positive charge ("hole") or are captured by the pyrimidines [thymine (T) and cytosine (C)], resulting in radical anion formation. During ionization events, all the bases are randomly ionized and "holes" (radical cations) are formed, which travel within DNA toward the base having lowest ionization potential, the order being guanine $(G)<$ adenine $(A)<$ cytosine $(C) \approx$ thymine $(T){ }^{2}$ Therefore, in a randomly ionized DNA double strand, the hole tunnels or hops from one base to

Radical and Radical Ion Reactivity in Nucleic Acid Chemistry, Edited by Marc M. Greenberg Copyright (C) 2009 John Wiley \& Sons, Inc. 
the next, finally localizing on guanine to form the guanine radical cation $\left(\mathrm{G}^{\bullet+}\right){ }^{1-3,7-9}$ Ionization radiation also induces holes on the sugar-phosphate backbone site that lead to two competitive reactions: (i) deprotonation of the sugar cation radical at a carbon site resulting in the formation of neutral sugar radicals at carbon $C_{1}^{\prime}$ to $C_{5}^{\prime}$ sites $^{23-28}$ and (ii) transfer of hole to a nearby base in DNA. ${ }^{28}$

Since most sugar radicals lead to DNA strand breaks, sugar radical formation in DNA becomes of crucial importance to the biological consequences of radiation. Recently, it has been found that irradiation of DNA by a high LET (linear energy transfer) radiation, a high-energy argon ion beam, ${ }^{23}$ produced a far higher yield of sugar radicals than was found by a low LET radiation, $\gamma$-irradiation. The authors report that the excess sugar radicals were created within the track core. ${ }^{23}$ The energy density in the track core is high and results in ionizations and excitations in close proximity. For this reason, it was hypothesized that excited states of radical cations might result in the neutral sugar radicals in the core of the ion track. To test this hypothesis, recent experiments in our laboratory were performed on the photoexcitation of guanine and adenine radical cations $\left(\mathrm{G}^{{ }^{+}}, \mathrm{A}^{\cdot+}\right)$ in DNA model systems. ${ }^{24-27}$ It was found that excited DNA base cation radicals formed high yield of sugar radicals which confirmed the proposed hypothesis. ${ }^{24-27}$

While strand breaks are biologically significant, it is combinations of DNA damages known as multiple damage sites (MDS) that are the most lethal type of DNA damage. Such combinations of single- and double-strand breaks and base damages with 10 base pairs are known to lead to irreparable damage because of the loss of local structural information. High-LET radiations ( $\alpha$ particles, atom ion beams, neutrons) are found to be about 10 times more damaging than the low-LET radiations such as $\beta$ particles, $X$ rays, and $\gamma$ rays in the production of such damage.

From the above discussion, it is evident that ionization and excitation are the initial events in DNA damage. As the damage unfolds from these initial events, the processes may become complex in nature; however, the simplicity of the initial events allow for a clear understanding of these initial processes. Thus ionization, excitation, and electron addition to DNA bases have been extensively treated by theoretical calculations using a variety of methods with density functional theory (DFT) perhaps the most useful to large systems. The advent of substantial computing power and the availability of inexpensive computational resources ${ }^{29}$ allows the application of more sophisticated level of theoretical calculation such as TD-DFT, Møller-Plesset perturbation theory (MP2), CCSD(T), and CASPT2 that can shed light on the underlying chemical processes controlling the DNA damage. A close agreement between theory and experiment is expected, given an appropriate use of theory. In this review we present recent investigations that employ theory to aid understanding of DNA base and sugar radical formation, via ionization, excitation, and electron attachment to DNA. Specific topics include (1) ionization energies and electron affinities of bases and base pairs, (2) excited states of radical DNA base cations and their roles in leading to sugar radicals, (3) the role of excited states of DNA base anion radicals in the formation of LEE (low-energy electron)-induced DNA single-strand breaks, (4) the nature of hole delocalization in adenine stacks systems including the usual stability of the dimer radical cation $\left(\mathrm{A}_{2}\right)^{\bullet+}$ and its importance to the unusual long-range hole transfer within 
A stacks in DNA, and (5) the prototropic equilibria found for the guanosine radical cation, which also modulates hole transfer in DNA.

\subsection{DIRECT EFFECT OF IONIZING RADIATION IN RADICAL ION FORMATION}

As described in the Introduction, the direct interaction of ionizing radiation with DNA initially creates "hole" (cation radical) in DNA and ejects an electron that is usually captured as an anion radical in DNA. Electron spin resonance (ESR) spectroscopy studies show that for $\gamma$-irradiated salmon testes DNA at $77 \mathrm{~K}$, the relative amounts of the observed initial ion radicals are: $35 \%$ guanine radical cation $\left(\mathrm{G}^{\bullet+}\right)$ with a small amount $(<5 \%)$ of adenine radical cation $\left(\mathrm{A}^{\bullet+}\right)$ with nearly equal amounts of thymine and cytosine radical anions $\left(\mathrm{T}^{\bullet-}, \mathrm{C}^{\bullet-}\right)$ summing to $\sim 45 \% .{ }^{30,10}$ The remaining fraction of $10-15 \%$ is made up of neutral radicals primarily on the sugar-phosphate backbone. ${ }^{30,10}$ The minimum energy required to form a radical cation is estimated from the ionization potential (IP), while the energy of formation for the anion radical is estimated from the electron affinity (EA) of the corresponding DNA base, sugar, and phosphate. The determination of these fundamental properties are of substantial importance, and much effort has been expended in this area.

Theoretical calculations of molecular structures of bases in their neutral and ionized radical states, their spin density distributions, and their IPs and EAs provide valuable information that aid interpretations of experiment. In Figure 1.1, the molecular structures of guanine $(\mathrm{G})$, adenine $(\mathrm{A})$, thymine $(\mathrm{T})$, cytosine $(\mathrm{C})$, uracil $(\mathrm{U})$ (present in RNA), and sugar moiety are shown.<smiles></smiles><smiles>Nc1ncc2nc[nH]c2n1</smiles><smiles>Nc1cc[nH]c(=O)n1</smiles>

Guanine (G)

Adenine (A)<smiles>[GeH3][GeH2][GeH3]</smiles><smiles>Cc1c[nH]c(=O)[nH]c1=O</smiles>

Thymine (T)<smiles>O=c1cccc[nH]1</smiles>

Uracil (U)

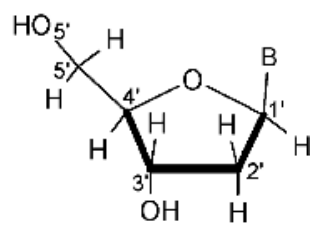

Sugar

FIGURE 1.1. Molecular structures of guanine (G), adenine (A), cytosine (C), thymine (T), uracil (U) and sugar moiety, present in DNA/RNA. In the sugar moiety, B shows the site of base attachment. 


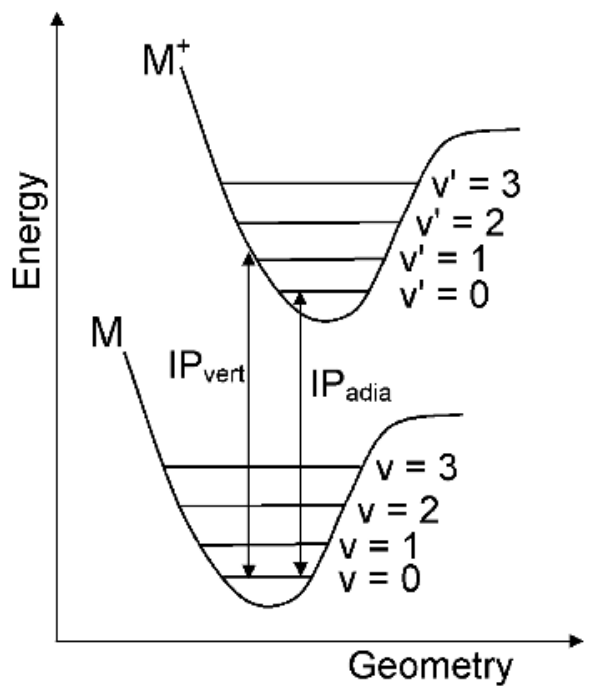

FIGURE 1.2. Diagram showing the definitions of vertical ionization potential $\left(\mathrm{IP}_{\mathrm{vert}}\right)$ and adiabatic ionization potential $\left(\mathrm{IP}_{\mathrm{adia}}\right)$.

\subsubsection{Ionization Potential of DNA Bases and Base Pairs}

The vertical ionization potential ( $\mathrm{IP}_{\mathrm{vert}}$ ) of DNA bases $\mathrm{G}, \mathrm{C}, \mathrm{A}$, and $\mathrm{T}$ in the gas phase has been measured experimentally using photoelectron spectroscopy by Hush and Cheung ${ }^{31}$ while the corresponding adiabatic ionization potential ( $\left(\mathrm{IP}_{\text {adia }}\right.$ ) values were measured by Orlov et al. ${ }^{32}$ using photoionization mass spectrometry in the gas phase. Recently, Kim and co-workers ${ }^{33}$ reported the ionization potential of thymine (T) using the high-resolution vacuum ultraviolet mass-analyzed threshold ionization (VUVMATI) spectroscopy. The ionization potential of a neutral molecule M is the energy required to remove an electron from the molecule. In Figure 1.2, theoretical estimates of the $\mathrm{IP}_{\mathrm{vert}}, \mathrm{IP}_{\mathrm{adia}}$ are shown. If the energies are zero point energy (ZPE)-corrected, the ionization potentials are referred to as $\mathrm{ZPE}$-corrected $\left(\mathrm{IP}_{\text {zero }}\right)$. Another quantity, the nuclear relaxation energy (NRE), calculated as the difference between IP $_{\text {vert }}$ and IP $_{\text {adia }}$, is of interest because it provides an additional energetic barrier to "hole" transfer within DNA. Figure 1.3 shows the experimental IPs of A, T, G, and C along with their NRE energies. Using different theoretical methods, the gas-phase ionization potential of DNA bases were also calculated. ${ }^{34-41}$ A comparison of the theoretically calculated IP values of G, A, C and T along with their corresponding experimental values are presented in Table 1.1. In Table 1.1, we see that both theory and experiment predict the same order of ionization potential of DNA bases as $\mathrm{G}<\mathrm{A}<\mathrm{C}<\mathrm{T}$.

The adiabatic ionization potentials of adenine and cytosine have been studied using $\operatorname{CCSD}(\mathrm{T}) / 6-311++\mathrm{G}(3 d f, 2 p)$ level of theory, ${ }^{38}$ and the corresponding values are in an excellent agreement with those calculated using experiment, see Table 1.1. Recently, Cauët et al..$^{39}$ used the MP2 method to calculate the vertical and adiabatic ionization potentials of DNA bases. In their study, they added another polarization function $\left(\alpha_{d}\right)$ 


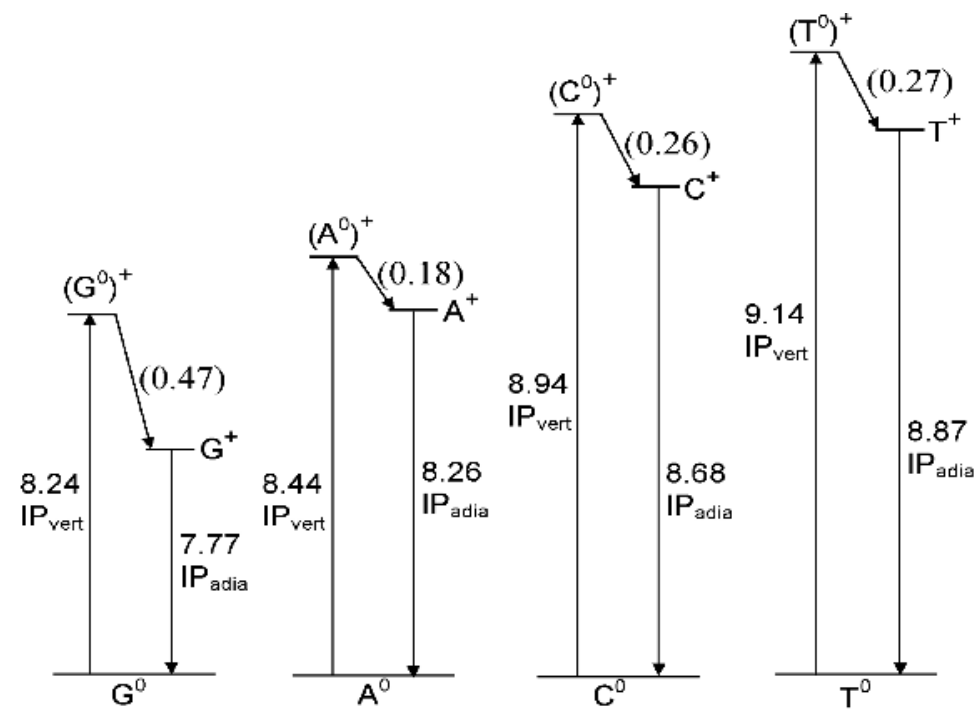

FIGURE 1.3. Experimentally estimated adiabatic and vertical ionization potentials of G, A, C, and $T$. The nuclear relaxation energy (NRE) is also shown in parentheses. $G^{0}, A^{0}, C^{0}$, and $T^{0}$ designate the neutral molecules.

for $\mathrm{C}, \mathrm{N}$, and $\mathrm{O}$ atoms to the standard $6-31 \mathrm{G}(d)$ basis set, resulting in the so-called 6$31 \mathrm{G}(2 d(0.8,0.1), p)$ basis set. Use of this basis set gave good values of IPs which are in close agreement to the experimental values, except for $\mathrm{IP}_{\mathrm{vert}}$ of adenine. Generally, it is found that unrestricted MP2 (UMP2) method for open-shell systems (here cation doublet state) is largely spin contaminated and as a result the calculated IPs were found to be quite high. ${ }^{40}$ In this context, Crespo-Hernandez et al. ${ }^{40}$ used projected MP2 (PMP2) method for the calculation of IPs of DNA bases, see Table 1.1. Recently, Yang et al. ${ }^{42}$ measured the ionization potentials of mono-, di-, and trinucleotide anions of A, T, G, and C using photodetachment-photoelectron (PD-PE) spectroscopy, and they found that $2^{\prime}$-deoxyguanosine $5^{\prime}$-monophosphate anion $\left(\mathrm{dGMP}^{-}\right)$has the lowest ionization potential among all the DNA nucleotides. In their study, the electron detachment occurred from a $\pi$ orbital of guanine base on $\mathrm{dGMP}^{-}$; however, for the other three nucleotide anions, the lowest ionization takes place from the phosphate group. This observation is likely valid for the gas phase but is not relevant to solutions where the solvation of the phosphate group makes it the DNA component of highest IE. Furthermore, it is well known that bases are the sites of the lowest ionization in DNA from numerous experimental studies, and the presence of solvation and counterions near the phosphate groups when included show this to be the case by theory. ${ }^{43,44}$

There are several factors such as base pairing, base stacking, and solvation in DNA that significantly affect the ionization potential of bases in DNA. It is well known that solvation lowers the ionization potentials of bases by several electron volts when compared to the corresponding gas-phase values. In a study, Kim et al. ${ }^{45}$ have found that ionization potentials of adenine and thymine decrease with the increasing number of hydrating water molecules and hydration by three water molecules decrease the 


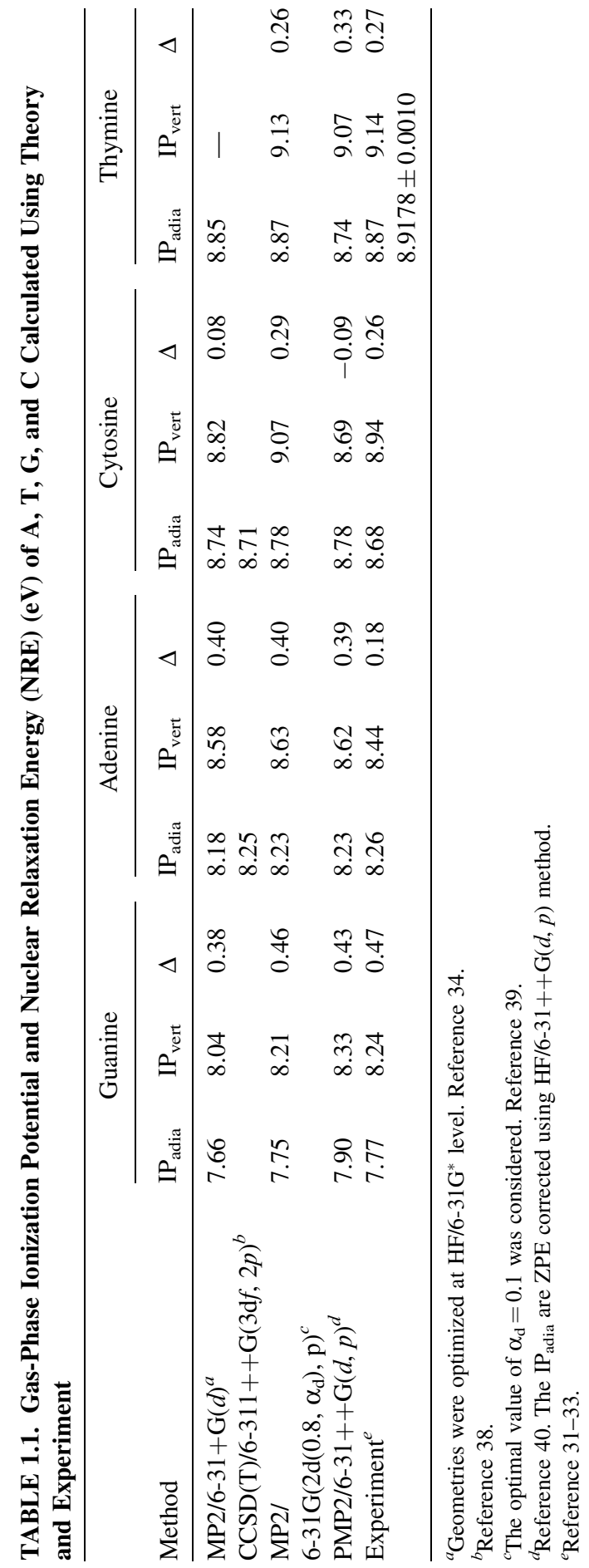


ionization potentials of $\mathrm{A}$ and $\mathrm{T}$ by $0.7 \mathrm{eV}$ than their gas-phase values. ${ }^{31-33}$ Recently, the vertical ionization potentials of $\mathrm{A}, \mathrm{T}, \mathrm{G}$, and $\mathrm{C}$ in aqueous medium was calculated by $\mathrm{Close}^{46}$ using polarized continuum model (PCM) and the projected MP2/6$31++\mathrm{G}(d, p)$ and $\mathrm{B} 3 \mathrm{LYP} / 6-31++\mathrm{G}(d, p)$ methods. After solvation energy correction of the electron $(-1.3 \mathrm{eV})$, both the methods gave similar values of ionization potentials of guanine 4.77 (4.71), adenine 5.08 (5.05), cytosine 5.24 (5.32), and thymine 5.36 (5.41) (the numbers in parentheses are the PCM-B3LYP calculated values). ${ }^{46}$ These calculated values use a unusual standard state for the ejected electron. An electron in water at the conduction band edge $\left(V_{0}\right)^{43}$ is employed as the final electron state not the gas-phase electron, and this lowers the IP by $1.3 \mathrm{eV}$. Without this correction the corresponding $\mathrm{IP}_{\mathrm{vet}}$ values at B3LYP/6-31++ $\mathrm{G}(d, p)$ level of calculation are $6.01(\mathrm{G})$, $6.35(\mathrm{~A}), 6.62(\mathrm{C})$, and $6.71(\mathrm{~T})$.

The ionization potentials of DNA bases in GC and AT hydrogen-bonded base pairs were calculated by Colson et al. ${ }^{47}$ using $\mathrm{HF} / 3-21 \mathrm{G}$ and $\mathrm{HF} / 6-31+\mathrm{G}(d) / / \mathrm{HF} / 3-21 \mathrm{G}$ methods in Koopmans' approximations which were further refined by $\mathrm{Li}$ et al. ${ }^{48,49}$ using the B3LYP method and the 6-31+G(d) basis set (Hutter and Clark ${ }^{50}$ and Bertran et al. $\left.{ }^{51}\right)$. The calculated IP ${ }_{\text {vert }}$ for GC and AT base pairs, by Li et al. ${ }^{48,49}$, were found to be 7.23 and $7.80 \mathrm{eV}$; however, the zero-point energy (ZPE)-corrected adiabatic IP of GC and AT were found to be 6.90 and $7.68 \mathrm{eV}$, respectively. The $\mathrm{IP}_{\text {adia }}$ values of GC and AT pairs due to Li et al. ${ }^{48,49}$ are in good agreement (within $0.2 \mathrm{eV}$ ) with those earlier calculated by Hutter and Clark ${ }^{50}$ and Bertran et al. ${ }^{51}$

The effect of hydration on the ionization potential of GC and AT base pairs was studied by Colson et al. ${ }^{52,53}$ using HF/3-21G and HF/6-31+G(d)//HF/3-21G methods and Koopmans' approximation. In the calculation, they used four water molecules to solvate the base pairs; and the calculated $\mathrm{IP}_{\text {vert }}$ of GC and AT base pairs, at HF/3-31G level of theory, were found to be 7.80 and $8.59 \mathrm{eV}$, respectively. However, the corresponding $\mathrm{IP}_{\mathrm{adia}}$, calculated at the $\mathrm{HF} / 6-31+\mathrm{G}(d) / / \mathrm{HF} / 3-21 \mathrm{G}$ level of theory, was found to be 6.53 and $7.45 \mathrm{eV}$. Strangely, these values were higher than the corresponding gas-phase ionization potential values of the GC and AT base pairs. ${ }^{52,53}$ Each water molecule acting as a hydrogen-bond donor to the base increases the IP, while each water molecule in the hydrogen-bond acceptor configuration with the base lowers the IP. ${ }^{52,53}$ Therefore, it seems that four water molecules in the calculation of Colson et al. ${ }^{52,53}$ were not enough to fully account for the solvation shell surrounding the base pairs, and most of the waters act as hydrogen-bond donors. ${ }^{53}$ Recently, Barnett et al. $^{54}$ studied the duplex DNA $d\left(5^{\prime}-(\mathrm{G}) n-3^{\prime}\right)$, for $n=2,3$, considering the crystallographic structures, counterions $\left(\mathrm{Na}^{+}\right)$near the phosphate group, and solvating water molecules. Their calculated values of vertical and adiabatic IPs are substantially lower than expected, perhaps as a result of the involvement of nonequilibrium conformations in local minima which place counterions in sites to lower the IPs. The ionization potentials of base pairs in the stacked conformation have also been studied theoretically. ${ }^{55-57}$ The vertical ionization potential of stacked bases and basepaired dinucleotides were calculated by Sugiyama and Saito ${ }^{57}$ using $3-21 G^{*}$ and 6$31 \mathrm{G}^{*}$ levels within Koopmans' approximation. With $6-31 \mathrm{G}^{*}$ level of theory, the ionization potentials of G, GG, GGG, and GGGG were found to be 7.75, 7.28, 7.07, $6.98 .^{57}$ The above discussion clearly shows that base pairing, stacking, hydration, and 
the local environment significantly affect the ionization potentials of the DNA bases, usually by lowering values.

\subsubsection{Acid and Base Properties of Ionized DNA Bases and Base Pairs}

Following radiation, the one-electron-oxidized purines $\left(\mathrm{G}^{\bullet+}, \mathrm{A}^{\bullet+}\right)$ and one-electronreduced pyrimidines $\left(\mathrm{C}^{\bullet-}, \mathrm{T}^{0^{-}}\right)$in DNA become quite reactive in comparison to their neutral forms. The oxidized purines become stronger acids and undergo deprotonation reactions, whereas the reduced pyrimidines become stronger bases and undergo protonation reactions. A competitive reaction to deprotonation for DNA base cation radicals is the addition of hydroxyl ions that form base hydroxyl adducts. This can lead to biologically significant damages such as 8-oxoG. In addition, electron-hole transfer and intra-base-pair proton transfer reactions also occur. ${ }^{58-60}$ This intra-base pair proton $\left(\mathrm{H}^{+}\right)$transfer in DNA can slow or stop charge transfer processes in DNA. ${ }^{58-61}$ Such proton transfer process strongly depends on the $\mathrm{p} K_{a}$ value of the base radical ion involved. Steenken ${ }^{58-60}$ first considered the proton transfer reactions between basepair ion radicals from experimental measurements on nucleoside ion radicals and concluded that acidity of the complementary oxidized purine base and basicity of the radical anion (pyrimidine base) would affect the extent of such a proton transfer process. ${ }^{58-61}$ Experimental values of the $\mathrm{p} K_{a}$ of $\mathrm{G}^{\bullet+}, \mathrm{A}^{\bullet+}, \mathrm{C}^{\bullet+}$, and $\mathrm{T}^{\bullet+}$ are $3.9,<1$ (strong acid), $\sim 4.0$, and 3.6. ${ }^{58-61}$ On the other hand, the $\mathrm{p} K_{a}$ of $\mathrm{C}^{\bullet-}$ and $\mathrm{T}^{\bullet-}$ were reported to be as $\geq 13.0$ (strong base) and $\geq 6.9$, respectively. ${ }^{58-61}$

Theoretical calculations of a $\mathrm{p} K_{a}$ is very sensitive and a modest change in energy can change the $\mathrm{p} K_{a}$ by several units. However, using the DFT method the $\mathrm{p} K_{a}$ values of oxidized DNA bases have also been calculated ${ }^{62-64}$ to reasonable accuracy. In a recent study, ${ }^{65}$ the $\mathrm{p} K_{a}$ of $\mathrm{A}^{\bullet+}$ was calculated as -0.3 using B3LYP/6-31G* method in reasonable agreement with experiment and shows that $\mathrm{A}^{\bullet+}$ should be a strong acid that deprotonates spontaneously in the presence of solvent. To confirm this, a hydration shell around the adenine base of deoxyadenosine radical cation $\left(\mathrm{dA}^{\bullet+}\right)$ was modeled by placing seven water molecules and optimized the geometry using the B3LYP/6$31 \mathrm{G}^{*}$ method, shown in Figure 1.4a. In the optimized structure of $\left(\mathrm{dA}^{\bullet+}+7 \mathrm{H}_{2} \mathrm{O}\right)$, it was found that in the presence of solvent the $\mathrm{N}_{6}-\mathrm{H}^{\prime}$ bond is elongated by $\sim 0.1 \AA$ as compared to the corresponding bond length in gas phase (see Figure 1.4a). Furthermore, the potential energy surface (PES) of the deprotonation of $\mathrm{N}_{6}-\mathrm{H}^{\prime}$ bond from the optimized structure of $\left(\mathrm{dA}^{\bullet+}+7 \mathrm{H}_{2} \mathrm{O}\right)$ was calculated by increasing the $\mathrm{N}_{6}-\mathrm{H}^{\prime}$ bond in the step size of $0.1 \AA$ from its equilibrium bond distance $(1.127 \AA$ ), see Figure 1.4a. From the PES, it was found that $\mathrm{N}_{6}-\mathrm{H}^{\prime}$ bond deprotonates in the presence of solvent without any barrier (for details see reference 65). Figure 1.4b, shows the formation of $\mathrm{H}_{3} \mathrm{O}^{+}$from the deprotonation of $\mathrm{dA}^{\bullet+}$. These theoretical results clearly predict that $\mathrm{dA}^{\bullet+}$ is a strong acid in agreement with experiment. ${ }^{58-61}$

The proton transfer reactions in GC and AT base pairs in their radical cation and anion states have been studied using Hartree-Fock (HF) and DFT methods. ${ }^{47,49-52}$ In these calculations the proton transfer energies were calculated as the difference between total energies of the ionized radical base pair before and after proton transfer. For GC and AT radical cations a small proton transfer energy $\sim 2 \mathrm{kcal} / \mathrm{mol}$ was 


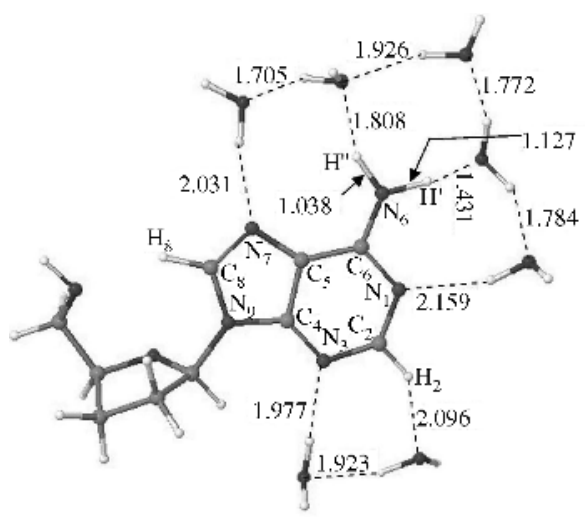

(a)

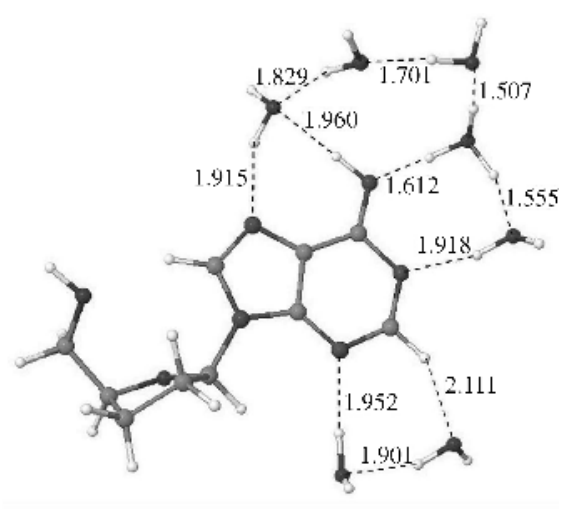

(b)

FIGURE 1.4. B3LYP/6-31G* optimized geometries of (a) deoxyadenosine cation radical in the presence of seven water molecules $\left(\mathrm{dA}^{\cdot+}+7 \mathrm{H}_{2} \mathrm{O}\right)$. The arrow on the elongated $\mathrm{N}_{6}-\mathrm{H}^{\prime}$ bond in this figure indicates that the elongation of this $\mathrm{N}_{6}-\mathrm{H}^{\prime}$ bond leads to deprotonation in the surrounding water shell (shown in b) and (b) hydronium ion $\left(\mathrm{H}_{3} \mathrm{O}^{+}\right)$formation from $\mathrm{A}^{\bullet+}$ owing to deprotonation of the structure in a. (Reprinted with permission from reference 65, J. Am. Chem. Soc. copyright 2008, American Chemical Society.)

predicted at the HF/3-21G ${ }^{* 47,52}$ and B3LYP/6-31G ${ }^{* 50,51}$ level of theories. Li et al. ${ }^{49}$ calculated the transition state and the corresponding enthalpy $(\Delta H)$ and the free energy $(\Delta E)$ for the inter-base proton transfer in GC and hypoxanthine-cytosine base pairs in their cation and anion states using the B $3 \mathrm{LYP} / 6-31+\mathrm{G}(d)$ method. In their calculation, the forward barrier for the proton transfer in GC radical anion was calculated to be $0.84 \mathrm{kcal} / \mathrm{mol}$; however, in GC radical cation, the corresponding barrier was found to be $2.96 \mathrm{kcal} / \mathrm{mol}{ }^{49}$ Also, the proton transferred radical cation $\left(\mathrm{G}^{\bullet+} \mathrm{C}^{\mathrm{PT}}\right)$ was found to be unstable by $\sim 1.25 \mathrm{kcal} / \mathrm{mol}$ compared to $\mathrm{G}^{\bullet+} \mathrm{C}$, while the proton transferred radical anion $\left(\mathrm{GC}^{\bullet-\mathrm{PT}}\right)$ was more stable by $3.73 \mathrm{kcal} / \mathrm{mol}$ than $\mathrm{GC}^{\bullet-} .^{49}$ Thus these calculations predict a highly favored proton transfer in GC anion radical and as predicted proton transfer from $\mathrm{G}$ to $\mathrm{C}$ has been observed on a nanosecond time scale using resonance-enhanced multiphoton ionization (REMPI) by Nir et al. ${ }^{66}$

\subsubsection{Gase-Phase Electron Affinities of DNA Bases and Base Pairs}

The electron affinity of a neutral molecule (M) is effectively the binding energy of an excess electron to the gas-phase molecule. The various processes that occur during electron molecule interactions are shown in Figure 1.5. Upon electron addition, the geometry of a neutral molecule undergoes nuclear relaxation to the geometry of the adiabatic anion $\left(\mathrm{M}^{-}\right)$. Electron attachment to the neutral molecule without nuclear relaxation yields the vertical electron affinity, and on relaxation the overall energy change gives the adiabatic electron affinity. If the anion is more stable than the neutral, positive electron affinities (VEA and AEA) are obtained, as shown in Figure 1.5. This topic has long been the subject of significant biological significance; and theoretical methods [including PPP, semiemperical (AM1), and DFT] and high-level methods 


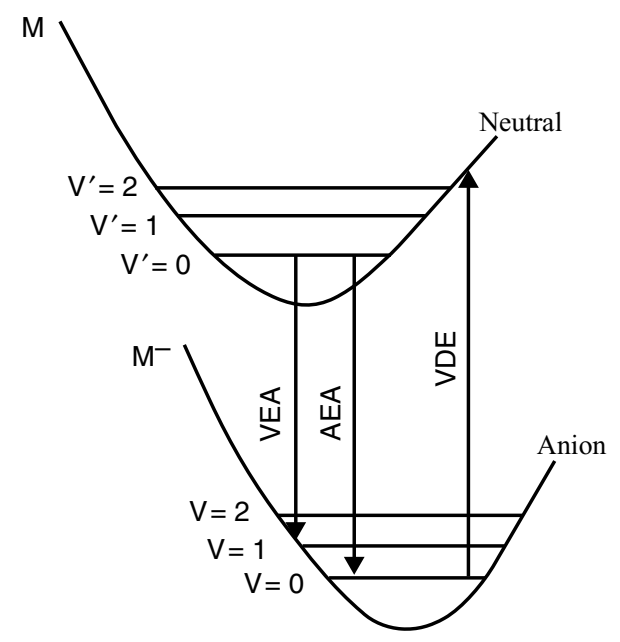

FIGURE 1.5. A diagram showing the potential energy surfaces (PES) of the formation of anionic molecule $\left(\mathrm{M}^{-}\right)$after electron attachment $\left(\mathrm{e}^{-}\right)$to the neutral molecule (M). Different processes occur during electron attachment: (i) Vertical electron affinity (VEA), (ii) adiabatic electron affinity (AEA), and (iii) vertical detachment energy (VDE) are shown. As can be inferred from the diagram, VEA and VDE represent the lower and upper bounds to AEA.

[such as MP2, and CCSD(T)] have been applied to evaluate the electron affinities of G, C, A, T, and U. ${ }^{34,67-73}$ From theory and experiment, it is well known that all the bases (A, T, G, C, and U) have negative vertical electron affinity values in gas phase. $^{34,67,74,75}$ While all the bases have negative VEA, the adiabatic electron affinities (AEAs) of bases $\left(\mathrm{C}, \mathrm{T}\right.$, and $\mathrm{U}$ ) are found to be near zero ${ }^{76-78}$ and still negative for $A$ and $G^{34,74,79}$ (see Table 1.1). Under solvation, the radical anionic states of the bases become substantially stabilized and trap the excess electron, thereby preventing autodetachment. Although the DFT method has been widely used to evaluate the electron affinities of DNA bases and base pairs, it is noted that DFT calculated values are overestimated by about 0.15 eVover experimental values. The use of high-level ab initio methods such as CCSD(T) and CBS-Q are found to provide the best estimates of AEAs. The experimental electron affinity values of A, $\mathrm{T}, \mathrm{G}, \mathrm{C}$, and $\mathrm{U}$ along with the best estimates from theory are presented in Table 1.1. In recent years, a number of reviews have appeared in the literature that cover the topic of DNA base EA. ${ }^{7,9,72}$

As described above, the vertical electron affinities (VEAs) of all the bases are negative, whereas their adiabatic electron affinities (AEAs) are near zero (Table 1.2). When the binding energy for "valence bound" anions is near zero or below, "dipolebound" (DB) anions can form in gas phase when the dipole moment of the molecule is larger than 2.3 debye. Dipole-bound binding energies are small, generally less than a $100 \mathrm{meV}^{76,78}$ with the electrons held in very diffuse states to the side of the molecule. Since each of the DNA bases have a sizeable dipole moment, each can form "dipolebound" anions in the gas phase. Because of negative VEAs and substantially small AEAs $(\sim 0)$ of the bases, the accurate prediction of EAs of bases using theory is a complex task. Also, the use of diffuse functions in the basis set mix the valence states 
TABLE 1.2. Experimental and Best Estimated Theoretical Gas-Phase Valence Electron Affinities of Bases (eV)

\begin{tabular}{|c|c|c|c|c|c|c|}
\hline \multirow[b]{3}{*}{ Bases } & & & \multicolumn{4}{|c|}{ Adiabatic } \\
\hline & \multicolumn{2}{|c|}{ Vertical } & \multicolumn{2}{|c|}{ Experiment } & \multirow{2}{*}{$\begin{array}{c}\text { DFT } \\
\text { Valence }\end{array}$} & \multirow{2}{*}{$\begin{array}{l}\text { Ab Initio } \\
\text { Valence }\end{array}$} \\
\hline & Experiment & Theory & Valence & $\mathrm{DB}^{e, g, l}$ & & \\
\hline G & $-0.74^{a}$ & $-1.25^{c}$ & - & & $-0.75^{h}$ & $-0.52^{i}$ \\
\hline A & $-0.54^{a}$ & $-0.74^{d}$ & - & & $-0.35^{h}$ & - \\
\hline $\mathrm{C}$ & $\begin{array}{l}-0.32^{a} \\
-0.55^{b}\end{array}$ & $\begin{array}{c}-0.55^{d} \\
-\end{array}$ & - & $85 \pm 8^{g}$ & $\begin{array}{l}-0.05^{h} \\
-\end{array}$ & $\begin{array}{c}-0.13^{j} \\
-\end{array}$ \\
\hline $\mathrm{T}$ & $\begin{array}{c}-0.29^{a} \\
-\end{array}$ & $\begin{array}{c}-0.30^{d} \\
-\end{array}$ & $\sim 0^{f}$ & $\begin{array}{l}69 \pm 7^{l} \\
62 \pm 8^{g}\end{array}$ & $\begin{array}{l}0.15^{h} \\
-\end{array}$ & $\begin{array}{l}0.02^{k} \\
-\end{array}$ \\
\hline $\mathrm{U}$ & $\begin{array}{l}-0.22^{a} \\
-0.30^{b}\end{array}$ & $\begin{array}{c}-0.27^{d} \\
-\end{array}$ & $\sim 0^{f}$ & $\begin{array}{l}93 \pm 7^{l} \\
86 \pm 8^{g}\end{array}$ & $\begin{array}{l}0.20^{h} \\
- \\
-\end{array}$ & $\begin{array}{l}0.002^{j} \\
0.040^{m} \\
-\end{array}$ \\
\hline
\end{tabular}

${ }^{a}$ Electron transmission spectroscopy (ETS) results due to Aflatooni et al. ${ }^{74}$ For G, VEA was estimated for keto tautomer from enol tautomer experimental value $(-0.46 \mathrm{eV})$ plus the calculated difference in total energies between the two tautomers $(0.28 \mathrm{eV})$.

${ }^{b}$ Rydberg electron transfer spectroscopy (RET) results due to Periquet et al. ${ }^{79}$

${ }^{c}$ Best estimate from B3LYP/D95V+(D) trends for other bases. ${ }^{70}$

${ }^{d} \mathrm{~B} 3 \mathrm{LYP} / 6-311 \mathrm{G}(2 d f, p)$ values due to Vera and Pierini ${ }^{69}$ and Wetmore et al. ${ }^{36}$

${ }^{e}$ Values are in milli-electron volts.

${ }^{f}$ Estimated from stable valence anion complexes-for example, U(Ar) ${ }^{-}$.

${ }^{g}$ Reference 78. Dipole-bound (DB).

${ }^{h}$ Best estimates from DFT basis set dependence study due to Li et al. ${ }^{70}$ DFT values are generally overestimated by $0.15 \mathrm{eV}$.

${ }^{i}$ Reference 82 .

${ }^{j}$ Calculated using CBS-Q. Reference 83.

${ }^{k} \mathrm{CCSD}(\mathrm{T})$ correction to MP2 complete basis set (CBS) limit including ZPE correction. See Reference 84 . ${ }^{l}$ References 76 and 78. Dipole-bound (DB).

${ }^{m}$ Reference 73 .

with "dipole-bound" states and do not provide a good estimate of the valence electron affinities. ${ }^{69,70}$ A number of theoretical methods are available in the literature to deal with the negative electron affinities of molecules. ${ }^{68-70}$ It is also found that use of a compact basis set that confines the electron to the molecular framework produces a good estimate of the VEA with absolute values estimated with interpolation techniques. ${ }^{34} \mathrm{Li}$ et al. ${ }^{70}$ used the B3LYP method and several basis sets and show the trends when diffuse states (dipole bound) mix with the valence states. However, in the presence of aqueous medium, these diffuse states are destabilized and valence anions are stabilized by several electron volts. As expected, experiments in aqueous phases using electron spin resonance (ESR) spectroscopy show that stable anion base radicals are found for all DNA bases. ${ }^{80,81}$

The electron affinities of isolated DNA bases change on base-pair formation. In this context, Bowen and co-workers ${ }^{85}$ studied the radical anions of AT and 9-methyl-A:1methyl-T (MAMT) using photoelectron spectroscopy (PES) and B3LYP/6-31+G** 

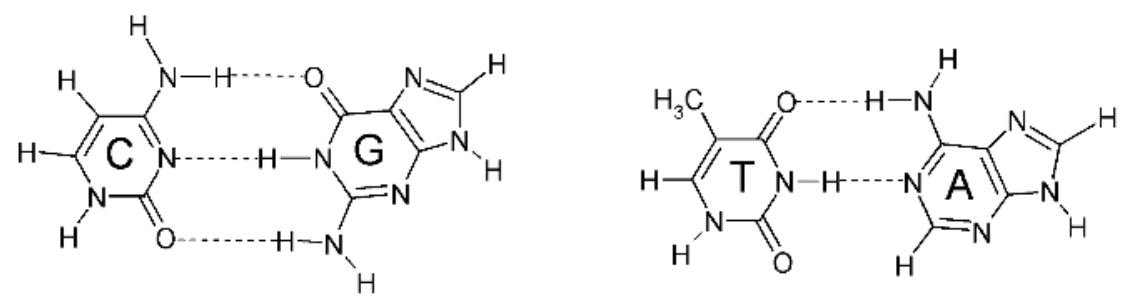

FIGURE 1.6. Diagram showing GC and AT base pairs in Watson-Crick conformation.

(6d) method. They calculated the vertical detachment energy (VDE) of the MAMT anion base pair as $0.77 \mathrm{eV}$, which corresponds very well to their experimental value. However, in AT radical anions the B3LYP/6-31+G** $(6 d)$ calculated value $0.89 \mathrm{eV}$ was quite different from the experimental value of $1.7 \mathrm{eV} .{ }^{85}$ However, they found a proton-transferred AT radical anion structure which has the VDE value comparable to the experimental value. The substantial positive VDE from this study demonstrates the occurrence of stable valence anion formation on base pairing. The excess electron was localized on the $\pi^{*}$ orbitals of thymine in both AT and MAMT radical anions as expected. The gas-phase electron affinities of AT and GC base pairs have been calculated by several other workers. ${ }^{48,86-88}$ For AT the AEAs lie in the range $0.30-0.36 \mathrm{eV}$, while for GC base pair the AEAs lie in the range $0.49-0.60 \mathrm{eV}$, respectively. In each case the electron localizes on the pyrimidine; thus, base pairing increases the electron affinity of $\mathrm{T}$ by $\sim 0.3 \mathrm{eV}$ and $\mathrm{C}$ by $\sim 0.6 \mathrm{eV}$. The larger increase in the $\mathrm{EA}$ of $\mathrm{C}$ over $\mathrm{T}$ on base pairing results from the fact that $\mathrm{G}$ provides two donor $\mathrm{H}$ bonds to $\mathrm{C}$, whereas A provides only one donor $\mathrm{H}$ bond to $\mathrm{T}$ (see Figure 1.6). Each donor $\mathrm{H}$ bond raises the $\mathrm{EA}$ of the recipient molecule by $0.1-0.3 \mathrm{eV}$.

A large change in electron affinity values and the nature of excess electron binding with $\mathrm{U}, \mathrm{T}$, and $\mathrm{C}$ have been observed experimentally with the addition of water molecules by Bowen and co-workers, ${ }^{77}$ Periquet et al., ${ }^{79}$ and Schiedt et al. ${ }^{78}$ These studies show that the first water increases the EA by $\sim 0.3 \mathrm{eV}$ and that subsequent waters have decreasing contributions as the number of waters increases, and for up to 5 waters the EAs of T, C, and U were estimated to be $1.1,1.0$, and $1.4 \mathrm{eV},{ }^{78}$ respectively. Interestingly, the experimentally observed dipole bound states of all the pyrimidine $(\mathrm{T}$, $\mathrm{C}$, and $\mathrm{U}$ ) radical anions in gas-phase transform to valence bound states on addition of a single water molecule and, as mentioned above, in an aqueous medium T, C, and U are predicted to have substantial positive valence electron affinities ${ }^{77-79}$ as found experimentally. ${ }^{80,81}$

The effect of bulk solvent on molecular ion radicals can be modeled by several methods including: (i) treating the solvent by the polarized continuum model (PCM) and (ii) placing a number of discrete water molecules around the molecule often followed by the PCM model for completeness. Though the former approach is simpler to study it lacks the hydrogen bonding between solute and solvent while the second approach takes into account the hydrogen bonding between solute and solvent (waters). However, this method is computationally very expensive and also misses the full effect of the solvent unless followed by a PCM calculation of the entire 
structure. Using the above-mentioned approaches, the electron affinities of DNA bases and base pairs have been studied in a number of publications in recent years. $^{70,89-98}$ Using B3LYP/DZP ++ level of theory, Schaefer and co-workers ${ }^{90-92}$ calculated the electron affinities of T, $\mathrm{C}$, and $\mathrm{U}$ in the presence of 1-5 waters and their calculated ZPE-corrected absolute electron affinities of $\mathrm{T}, \mathrm{U}$, and $\mathrm{C}$ with 5 waters were calculated to be $0.65,0.74$, and $0.61 \mathrm{eV} .^{90-92}$ respectively. However, using the PCM model and the B3LYP/D95V+(D) method, Li et al. ${ }^{70}$ calculated the AEAs of G, C, A, $\mathrm{T}$, and $\mathrm{U}$ as $1.01,1.89,1.53,2.06$, and $2.15 \mathrm{eV}$, respectively. A large difference between these two calculations is obvious because former ${ }^{90-92}$ calculations lack the bulk solvent effect. In another study, AEA of the thymidine monophosphate-adenine ( $5^{\prime}$-dTMPHA) pair was calculated using the PCM model and the B3LYP/DZP + method as $2.05 \mathrm{eV},{ }^{93}$ while the AEA of an AT base pair in the presence of 13 waters was predicted to be $0.97 \mathrm{eV}$ at B3LYP/6-31+ $\mathrm{G}^{*}$ level of theory. ${ }^{97}$ In a recent study, ${ }^{98}$ the EA of GC base pair was also calculated using B3LYP/6-31+ $\mathrm{G}^{*}$ method in the presence of 6 and 11 waters and ZPE-corrected AEAs were found to be 0.74 and $0.95 \mathrm{eV}$, respectively. However, the incorporation of the bulk solvent (water) through the PCM model increased the AEAs of these $\left(\mathrm{GC}+6 \mathrm{H}_{2} \mathrm{O}\right.$ and $\left.\mathrm{GC}+11 \mathrm{H}_{2} \mathrm{O}\right)$ complexes to $1.77 \mathrm{eV}$. In this study, surprisingly it was found that the hydration shell initially destabilizes the GC base pair toward electron capture as a transient anion. Energetically unstable diffuse states $\left(\sigma^{*}\right.$ orbitals) in the hydration shell were suggested to provide an intermediate state for the excess electron before molecular reorganization of the water molecules results in a stable base-pair anion formation. To confirm this conclusion, the first excited state of the vertical radical anion of $\mathrm{GC}+11 \mathrm{H}_{2} \mathrm{O}$ complex was calculated using time-dependent density functional theory (TD-DFT) using TD-BHandHLYP/ $6-31+\mathrm{G}^{*}$ level of theory, and a very small transition energy $0.33 \mathrm{eV}$ having transition $\operatorname{SOMO}(\pi) \rightarrow \operatorname{LUMO}\left(\sigma^{*}\right)$ in nature with a small oscillator strength was found (see Figure 1.7). In adiabatic state, the excess electron localized on the $\pi$ orbitals of the cytosine as expected. In the adiabatic state, it is also found that a water molecule was hydrogen-bonded with the $\mathrm{C}_{6}$ atom of cytosine, as shown by an arrow in Figure 1.7c.

\subsubsection{Role of Excited States in LEE-Induced Strand Break Formation}

Interaction of low-energy electrons (LEEs) with DNA is a subject of significant biological importance, and in recent years it has been treated extensively using experiment ${ }^{1-22,99-102}$ and theory. ${ }^{103-126}$ It is now recognized as a component of the complex processes leading to radiation induced DNA damage. In this context, the recent experiments of Sanche and co-workers ${ }^{12,100}$ showing that low-energy electrons in the energy range $0-4 \mathrm{eV}$ (below the ionization threshold of DNA) can induce strand breaks in DNA attracted intense interest because it represents a new mechanism of strand breaks formation in DNA. Recent experiment by Illenberger and co-workers ${ }^{11}$ also confirmed that LEEs in the subexcitation energy $(<3 \mathrm{eV})$ effectively decomposes uracil in gas phase. Thus, from these experiments it is well established that these LEEs induce a variety of DNA damage such as (i) hydrogen atom loss from base, (ii) singlestrand break, ${ }^{12,13,100}$ (iii) glycosidic bond cleavage, ${ }^{13,16}$ and (iv) fragmentation of 


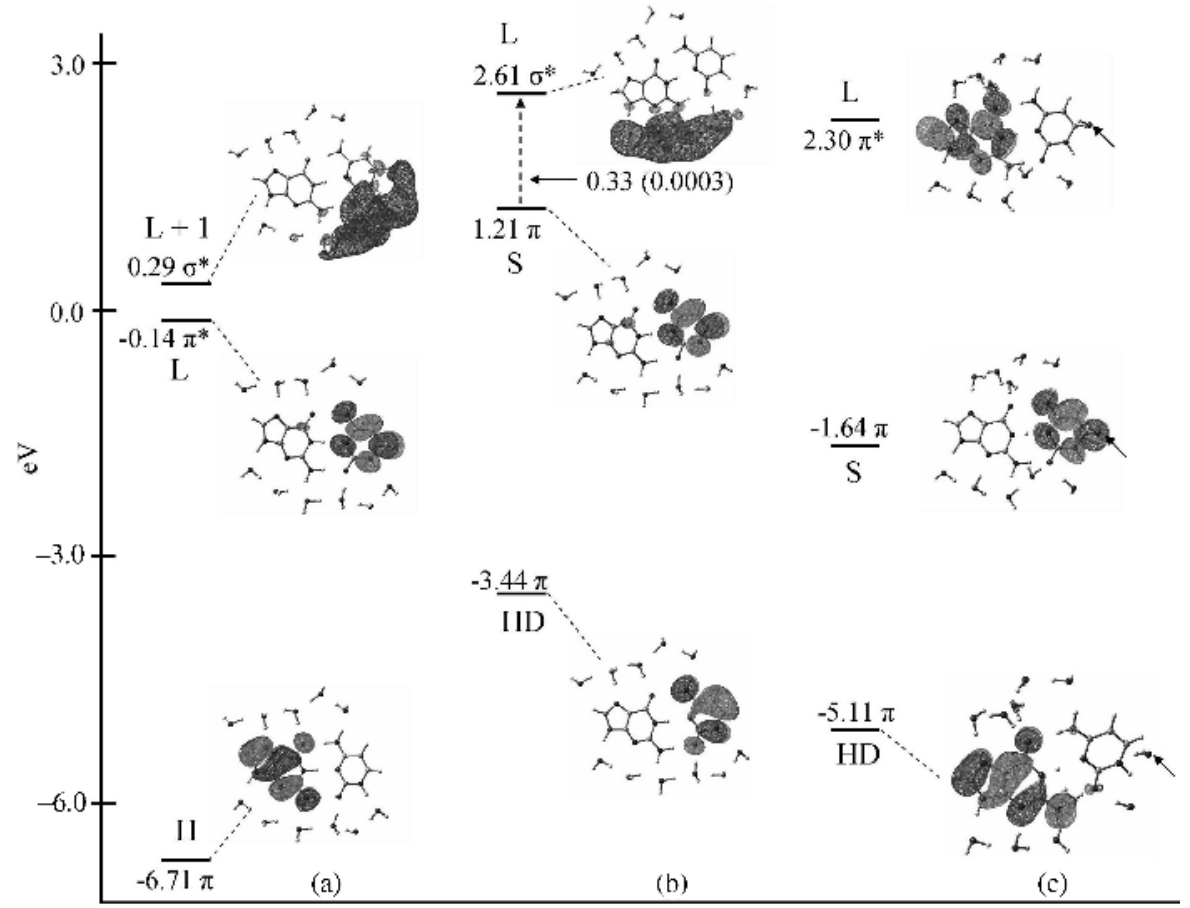

FIGURE 1.7. Plots of HOMO (H), HDMO (HD), LUMO (L), and SOMO (S) of GC- $11 \mathrm{H}_{2} \mathrm{O}$ in (a) neutral, (b) vertical (TNI), and (c) adiabatic radical anion along with respective molecular orbital (MO) energies (eV) calculated using the BHandHLYP/6-31+ $\mathrm{G}^{* *} / / \mathrm{B} 3 \mathrm{LYP} / 6-31+\mathrm{G}^{* *}$ method. The TD-BHandHLYP/6-31+ $\mathrm{G}^{* *}$ calculated first vertical excitation energy (oscillator strength) between $\mathrm{S}(\pi) \rightarrow \mathrm{L}\left(\sigma^{*}\right)$ is also shown by a broken arrow in part b. In part c, an arrow shows the location of the water molecule hydrogen bonded with the $\mathrm{C}_{6}$ atom of cytosine. $\mathrm{HDMO}=$ Doubly occupied highest molecular orbital. (Reprinted with permission from reference 98, J. Phys. Chem., copyright 2008, American Chemical Society.)

deoxyribose. ${ }^{21}$ Based on experiments, two types of mechanisms have been proposed which lead to dissociation processes: (i) Dissociative electron attachment (DEA) occurs in which LEEs are initially captured by the DNA components (bases, deoxyribose, and phosphate) to form transient negative ions (TNI) ${ }^{19-22,101,102}$ resulting in dissociation at that site. (ii) LEEs are initially captured by the bases into their $\pi^{*}$ MOs (shape resonance) and transferred to the sugar-phosphate group resulting in strand breaks. ${ }^{100}$

A number of theoretical papers have been appeared in the literature ${ }^{103-126}$ that elucidate mechanisms of LEE-induced strand break formation in DNA. Simons's group ${ }^{108-111}$ first proposed the "electron-induced" indirect mechanism of strand breaks formation using $5^{\prime}$-dTMP and $5^{\prime}$-dCMP as model systems. In their model, ${ }^{108-111}$ they proposed that initially an excess electron is captured into the $\pi^{*}$ MOs (shape resonance) of thymine or cytosine base in $5^{\prime}$-dTMP and $5^{\prime}$-dCMP; and during elongation of the $\mathrm{C}-\mathrm{O}$ bond the electron transfers to the $\sigma^{*}$ orbital of $\mathrm{C}_{5^{\prime}}-\mathrm{O}_{5^{\prime}}$ 
bond in the sugar-phosphate group, leading to $\mathrm{C}-\mathrm{O}$ bond cleavage $\mathrm{e}^{108-111}$ Later, Gu et al. ${ }^{112,113}$ refined the calculations of Simons et al. ${ }^{108-111}$ using the B3LYP/DZP++ level of theory and calculated the transition state for the dissociation of $\mathrm{C}_{5^{\prime}}-\mathrm{O}_{5^{\prime}}$ and $\mathrm{C}_{3^{\prime}}-\mathrm{O}_{3^{\prime}}$ bonds in pyrimidine nucleotides anion radicals in their adiabatic states and supported the proposed mechanism of Simons et al. ${ }^{108-111}$ It is clearly evident that these studies proposed the occurrence of strand breaks from trapped electron into the $\pi$ orbital on the base. However, it is well known that in a solvent environment, when an electron is stabilized in the $\pi$ orbital on the base, no strand breaks are found. ${ }^{127}$ This has also been supported by a recent study using B3LYP/6-31G $\mathrm{G}^{* *}$ method, in which the $\mathrm{C}_{5^{\prime}}-\mathrm{O}_{5^{\prime}}$ bond cleavage of a $5^{\prime}$-dTMP radical anion was calculated in the presence of 11 water molecules, and the phosphate group was neutralized by a $\mathrm{Na}^{+}$counterion. ${ }^{115}$ This study ${ }^{115}$ clearly demonstrated that under solvation the barrier height of $\mathrm{C}_{5^{\prime}}-\mathrm{O}_{5^{\prime}}$ bond cleavage was calculated to be almost two times the corresponding gas-phase value. Also, from the singly occupied molecular orbital (SOMO) plot, it was found that transfer of excess electron from thymine to the $\mathrm{C}-\mathrm{O}$ bond did not take place even at the transition state. ${ }^{115} \mathrm{Li}$ et al. ${ }^{104}$ proposed the direct mechanism of strand breaks formation in DNA by considering the sugar-phosphate-sugar (S-P-S) model without a base moiety using B3LYP/6-31+ $\mathrm{G}(d)$ level of theory and calculated the barrier height $\left(\sim 10 \mathrm{kcal} / \mathrm{mol}\right.$ ) for $\mathrm{C}_{5^{\prime}}-\mathrm{O}_{5^{\prime}}$ and $\mathrm{C}_{3^{\prime}}-\mathrm{O}_{3^{\prime}}$ bonds dissociation. In their model, they proposed the direct attachment of an excess electron to the sugar-phosphate group, leading to strand breaks. However, the calculated spin density distributions in this model showed a "dipole bound" anionic state rather than a valence bound state. 7, 104 Nevertheless, the low energy for dissociation shows that a weakly associated excess electron has the potential to fragment the deoxyribose backbone.

Though these theoretical models aid our understanding of strand break formation, they do not answer several important questions such as: (i) What is the role of initially formed transient negative ion (TNI)? and (ii) What is the role of various TNI excited states created during the low-energy electron-molecule interaction in strand breaks formation? These aspects have been investigated in recent studies. ${ }^{115,116}$ Using the B3LYP method and $6-31 \mathrm{G}^{*}$ and $6-31++\mathrm{G}^{* *}$ basis sets, the potential energy surfaces (PESs) of $\mathrm{C}_{5^{\prime}}-\mathrm{O}_{5^{\prime}}$ bond dissociation in $5^{\prime}$-dTMPH radical anion were calculated in both adiabatic (relaxed anion) and vertical (TNI) states. ${ }^{115}$ It was found that the barrier height of $\mathrm{C}_{5^{\prime}}-\mathrm{O}_{5^{\prime}}$ bond dissociation in the vertical (TNI) state was lower than that in the adiabatic state. Since during TNI formation the unoccupied molecular orbitals (UMOs) of neutral 5'-dTMPH molecule are available to capture the excess electron, the first few UMOs of $5^{\prime}$-dTMPH were also calculated and their orbital energies were scaled to the available experimental values. ${ }^{74}$ The scaled orbital energy values of five UMOs of $5^{\prime}$-dTMPH and their nature were calculated as $0.53\left(\pi_{1}{ }^{*}\right), 1.56\left(\pi_{2}{ }^{*}\right)$, $1.80\left(\sigma_{1}^{*}\right), 2.23\left(\sigma_{2}{ }^{*}\right)$, and $2.64\left(\sigma_{3}{ }^{*}\right)$, respectively, and $\pi^{*}$ and $\sigma^{*}$ orbitals were localized on the thymine base and on the sugar-phosphate group, respectively. Form this study, ${ }^{115}$ it was evident that below $2 \mathrm{eV}$ the orbitals on a phosphate group as well as on a base are available to capture the LEEs. Therefore, it seems that during TNI formation the lowest UMOs will excite the vibrational mode and result in the strand breaks.

It is well known that during electron-molecule interaction, different excited states are also involved. Their study can provide important information about the energy and 
nature of these states, which are those produced after capture the electron. Using the time-dependent density functional theory (TD-DFT), ${ }^{116}$ the excited states of the anion radical of 5'-dTMPH as a model of DNA were studied recently. ${ }^{116}$ The geometries of $5^{\prime}$-dTMPH molecule in their neutral and radical anionic states were optimized using the B3LYP/6-31G* method, and the lowest vertical excited states were calculated using the B3LYP and BHandHLYP (BH\&HLYP) methods using a 6-31G* basis set. In this study, ${ }^{116}$ the use of a $6-31 G^{*}$ (compact) basis set was emphasized because LEE resonances form TNIs, which are equivalent to the excited states of electron adduct of the parent neutral molecule. Since these resonances can be in continuum, the use of a compact basis set avoids the mixing of valence states to the continuum states. ${ }^{70}$ Also, the suitability of the TD-B3LYP/6-31G* and TD-BH\&HLYP/6-31G* methods for the calculation of excited states were extensively tested for several anion radicals for which experimental or theoretically calculated values were available (for details see supporting information of reference 116). Furthermore, both the methods were also tested to calculate the excitation energies for DNA/RNA bases for which the experimental shape resonance values are available ${ }^{74}$ (see Table 1.3). Both methods were found suitable for the test cases, but for the excited-state calculation of the $5^{\prime}$-dTMPH radical anion the TD-BH\&HLYP/6-31G* method was found to be more appropriate than the TD-B3LYP/6-31G* method. The failure of the B3LYP method is well known because it underestimates the long-range Coulomb interactions in charge transfer states. However, the use of increased Hartree-Fock exchange 50\% in BH\&HLYP over 20\% in B3LYP is found to be suitable to describe the long-range charge transfer states. Although in this class of study, ${ }^{116}$ charge transfer states are not created during excitation and only electron transfer between the nominally neutral portions of the molecule occurs. In view of this, the excited states of $5^{\prime}$-dTMPH radical anions in vertical and adiabatic radical anion states were calculated using the TD-BH\&HLYP/6-31G* method. In this work, the PESs of $\mathrm{C}_{5^{\prime}}-\mathrm{O}_{5^{\prime}}$ bond dissociation in $5^{\prime}$-dTMPH radical anions was stretched from their equilibrium bond length to $2.0 \AA$ in the step size of $0.1 \AA$, respectively. At each fixed $\mathrm{C}_{5^{\prime}}-\mathrm{O}_{5^{\prime}}$ bond length on the PES, the lowest excited states were calculated. In Figure 1.8, the vertical excited states of $5^{\prime}$-dTMPH radical anions in the adiabatic state are shown. In the adiabatic state, TD-BH\&HLYP predicted three lowest excitation energies as $\pi(\mathrm{T}) \rightarrow \pi(\mathrm{T})^{*}, \pi(\mathrm{T}) \rightarrow \sigma(\mathrm{PO} 4)^{*}$, and $\pi(\mathrm{T}) \rightarrow \sigma(\mathrm{S})^{*}$ type (here $\mathrm{T}, \mathrm{PO}_{4}$, and $\mathrm{S}$ refer to thymine, phosphate, and sugar group as shown in Figure 1.8) having transition energies $3.03,3.40$, and $3.85 \mathrm{eV}$, respectively. Also, these transitions are dominant one-electron excitations having contributions of about $61 \%, 87 \%, 87 \%$, respectively.

As already mentioned, TNI formation plays an important role in the DEA mechanism leading to strand breaks and resonance formation. ${ }^{21,74,115}$ Thus, the excited states of $5^{\prime}$-dTMPH radical anions were calculated at the optimized geometry of neutral 5'-dTMPH (TNI formation) using the TD-BH\&HLYP/6-31G* method as shown in Figure 1.9. The TD-BH\&HLYP/6-31G*-calculated lowest three transitions were found to be $\pi(\mathrm{T}) \rightarrow \sigma(\mathrm{PO} 4)^{*}, \pi(\mathrm{T}) \rightarrow \pi(\mathrm{T})^{*}$, and $\pi(\mathrm{T}) \rightarrow \sigma(\mathrm{S})^{*}$ in nature, having transition energies $1.42,1.68$, and $2.06 \mathrm{eV}$, respectively. The calculated second transition $\pi(\mathrm{T}) \rightarrow \pi(\mathrm{T})^{*}(1.68 \mathrm{eV})$ is found to be in good agreement with the 
TABLE 1.3. Vertical Excitation Energies $(\Delta E, \mathrm{eV})$ of Transient Negative Ion (TNI) of DNA/RNA Bases Calculated Using TD-B3LYP/6-31G* and TD-BH\&HLYP/6-31G* Methods and Their Comparison with Available Experimental Values ${ }^{a}$

\begin{tabular}{|c|c|c|c|c|}
\hline \multirow[b]{2}{*}{ Transition } & \multirow[b]{2}{*}{ Molecule } & \multicolumn{3}{|c|}{$\Delta E$} \\
\hline & & B3LYP & BH\&HLYP & Experiment ${ }^{b, c}$ \\
\hline- & Uracil & - & - & $0.22\left(\pi_{1}^{*}\right)$ \\
\hline$\pi \rightarrow \pi^{*}$ & & 1.33 & 1.85 & $1.58\left(\pi_{2}^{*}\right)$ \\
\hline$\pi \rightarrow \pi^{*}$ & & 4.27 & 4.73 & $3.83\left(\pi_{3}{ }^{*}\right)$ \\
\hline- & Thymine & - & - & $0.29\left(\pi_{1}^{*}\right)$ \\
\hline$\pi \rightarrow \pi^{*}$ & & 1.38 & 1.89 & $1.71\left(\pi_{2}^{*}\right)$ \\
\hline$\pi \rightarrow \pi^{*}$ & & 3.86 & 4.46 & $4.05\left(\pi_{3}{ }^{*}\right)$ \\
\hline- & Cytosine & - & - & $0.32\left(\pi_{1}^{*}\right)$ \\
\hline$\pi \rightarrow \pi^{*}$ & & 1.55 & 1.91 & $1.53\left(\pi_{2}^{*}\right)$ \\
\hline$\pi \rightarrow \pi^{*}$ & & 4.47 & 5.06 & $4.50\left(\pi_{3}^{*}\right)$ \\
\hline- & Adenine & - & - & $0.54\left(\pi_{1}^{*}\right)$ \\
\hline$\pi \rightarrow \pi^{*}$ & & 0.88 & 1.0 & $1.36\left(\pi_{2}^{*}\right)$ \\
\hline$\pi \rightarrow \pi^{*}$ & & 1.89 & 1.86 & $2.17\left(\pi_{3}^{*}\right)$ \\
\hline- & $5^{\prime}-\mathrm{dTMPH}^{d}$ & - & - & $(0.53 \mathrm{~T})^{d}$ \\
\hline$\pi \rightarrow \pi^{*}$ & & 1.16 & 1.68 & $(1.56 \mathrm{~T})^{d}$ \\
\hline$\pi \rightarrow \sigma^{* e}$ & & 0.18 & 1.42 & $\left(1.80 \mathrm{PO}_{4}\right)^{d}$ \\
\hline$\pi \rightarrow \sigma^{* e}$ & & 0.70 & 2.06 & $(2.23 \mathrm{~S})^{d}$ \\
\hline
\end{tabular}

${ }^{a}$ Transition energies of radical anions were calculated at the optimized neutral geometry of the molecules.

${ }^{b}$ Energies of the shape resonances in the electron transmission spectroscopy (ETS) experiment.

Reference 74 .

${ }^{c} \pi_{1}{ }^{*}$ corresponds to the energy of the singly occupied molecular orbital (SOMO), and its difference with $\pi_{2}{ }^{*}$ and $\pi_{3}{ }^{*}$ orbital energies gives the estimate of the transition energies.

${ }^{d}$ Scaled B3LYP orbital energies (VOE). Reference 115.

${ }^{e}$ Electron transfers from thymine $(\pi)$ to $\mathrm{PO}_{4}$ and sugar $(\sigma)$ part of $5^{\prime}$-dTMPH. (Reprinted with permission from reference 116, J. Am. Chem. Soc., copyright 2008, American Chemical Society.).

experimental ETS value $\left(1.71 \pi_{2}{ }^{*}\right)$ of thymine ${ }^{74}$ (see Table 1.3 ). This also confirms the accuracy of the TD-BH\&HLYP/6-31G* calculated excitation energy for the second $\pi^{*}$ surface (see Figure 1.9). Also, from Figures 1.8 and 1.9, it is clearly evident that SOMO is $\pi$ type in ground state and is localized on the thymine base as found by others ${ }^{103,105,108-115}$ and known from experiment. The barrier height for $\mathrm{C}_{5^{\prime}}-\mathrm{O}_{5^{\prime}}$ bond dissociation (in ground state) increases with the elongation of $\mathrm{C}_{5^{\prime}}-\mathrm{O}_{5^{\prime}}$ bond to the transition state (TS) and their values in adiabatic and in vertical (TNI) states are 23.3 and $18.7 \mathrm{kcal} / \mathrm{mol}$ as shown in Figures 1.8 and 1.9. It is also found that the first and second excited-state surfaces in the adiabatic state (Figure 1.8) and the second and third excited-state surfaces in the vertical state (Figure 1.9) show the bound character with the increase of $\mathrm{C}_{5^{\prime}}-\mathrm{O}_{5^{\prime}}$ bond. However, the second excitedstate surface in the adiabatic state (Figure 1.8) and the first excited-state surface in the vertical state (Figure 1.9) show the dissociative nature. Such a dissociative nature of $\pi \rightarrow \sigma^{*}$ in the excited state has already been established for a number of molecules. ${ }^{128-130}$ This study clearly predicts that a $<2 \mathrm{eV}$ electron can directly attach to the sugar-phosphate group during TNI formation (Figure 1.9) and cause 


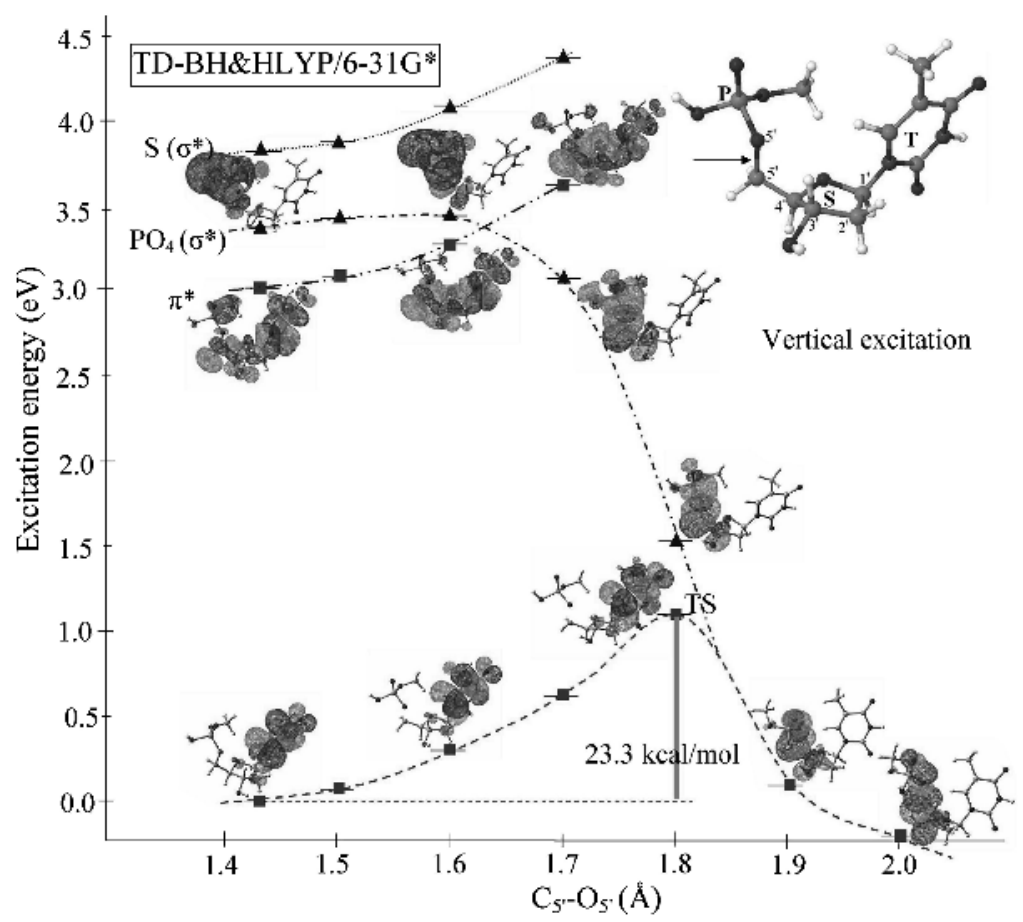

FIGURE 1.8. Lower curve shows the adiabatic ground-state potential energy surface for $\mathrm{C}_{5^{\prime}}-\mathrm{O}_{5^{\prime}}$ bond dissociation in the 5'-dTMPH radical anion calculated using BH\&HLYP/6-31G* . Upper curves show the vertical excitation energies calculated using TD-BH\&HLYP/6-31G* method. The lowest $\pi \pi^{*}$ state $(\mathbf{\square})$ and lowest $\pi \sigma^{*}$ states $(\boldsymbol{\Delta})$ are shown. The SOMO in ground state and MOs involved in excitations are shown as well. Energies and distances are given in electron volts and angstroms, respectively. (Reprinted with permission from reference 116, $J$. Am. Chem. Soc., copyright 2008, (American Chemical Society.)

strand breaks formation in DNA. The excited states of $\sigma^{*}$ symmetry $\left(\pi(\mathrm{T}) \rightarrow \sigma(\mathrm{PO} 4)^{*}\right.$ transitions) are not populated directly, owing to their short lifetimes; however, they can be populated through vibronic coupling with the neighboring $\pi^{*}$ states $\left(\pi(\mathrm{T}) \rightarrow \pi(\mathrm{T})^{*}\right)$. Thus, $\pi^{*}$ and $\sigma^{*}$ coupling would lead to a rapid dissociation process. The temporary anion states of trimethyl phosphate and several $\mathrm{P}=\mathrm{O}$ group containing compounds were recently studied by Burrow et al. ${ }^{131}$ using ETS, and the authors also concluded that resonances on phosphate groups are delocalized and $\sigma^{*}$ in nature. Recently, the calculations on electron scattering from A and B forms of DNA model due to Caron and Sanche ${ }^{122}$ concluded that irrespective of the internal electron diffractions in DNA, the capture probability of electron is much larger on the phosphate group than the other components. Also, the yields of single- and double-strand breaks induced by $0-4 \mathrm{eV}$ incident electrons were studied by Martin et al., ${ }^{100}$ and they found two peaks at electron energies $0.8 \pm 0.3$ and $2.2 \mathrm{eV}$. The TD-BH\&HLYP/6-31G*calculated first transition energy $\pi(\mathrm{T}) \rightarrow \pi(\mathrm{T})^{*}(1.7 \mathrm{eV})$ of TNI is in reasonable agreement with the observe second peak at $2.2 \pm 0.3 \mathrm{eV} .{ }^{100}$ 


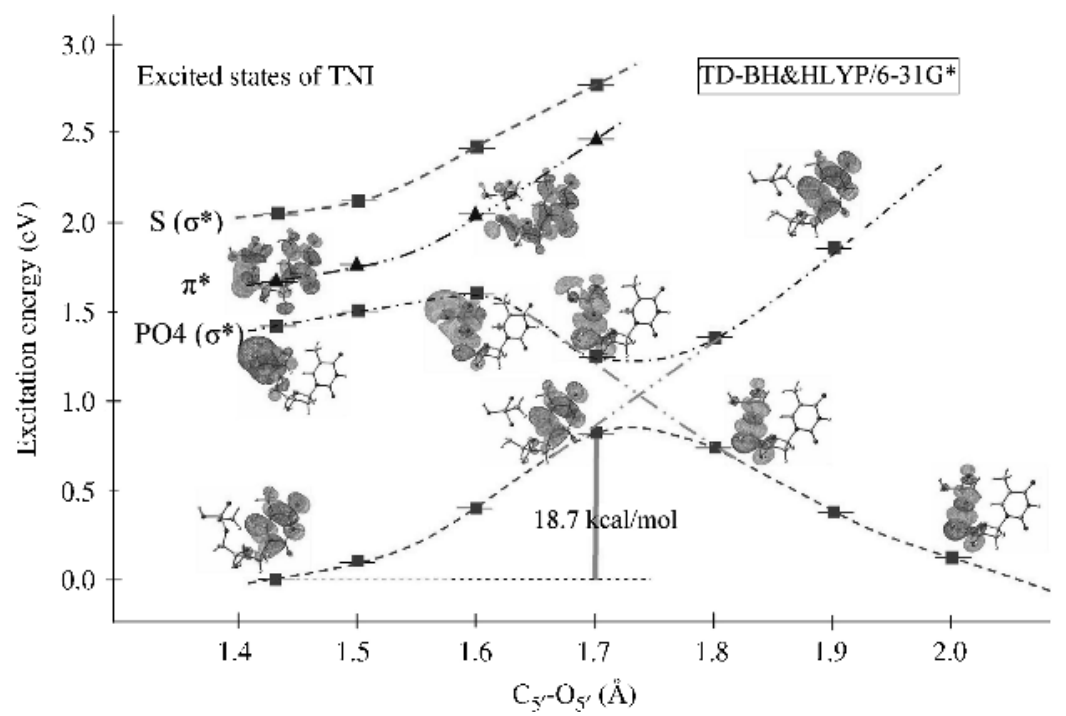

FIGURE 1.9. Lower curve: Potential energy surface (PES) of the $5^{\prime}$-dTMPH transient negative ion (TNI); calculated in the neutral optimized geometry of $5^{\prime}$-dTMPH with $\mathrm{C}_{5^{\prime}}-\mathrm{O}_{5^{\prime}}$ bond elongation. SOMO is shown at selected points. Upper curves: Calculated vertical excitation energies of the radical anion at each point along the PES, MOs involved in excitations are also shown. Energies and distances are given in electron volts and angstroms, respectively. The lowest $\pi \pi^{*}$ state $(\boldsymbol{\Lambda})$ and lowest $\pi \sigma^{*}$ states ( $(\mathbf{\square})$ are shown. (Reprinted with permission from reference 116, J. Am. Chem. Soc., copyright 2008, American Chemical Society.)

\subsection{FORMATION OF SUGAR RADICALS VIA PHOTOEXCITATION OF ONE-ELECTRON OXIDIZED NUCLEOSIDES AND OLIGOMERS}

Sugar radicals are formed in relatively low amounts (10-15\% of all radicals) in $\gamma$ irradiated double-stranded DNA at $77 \mathrm{~K}$ while DNA base ion radicals constitute the major radical species (85-90\%). ${ }^{80,23,132}$ However, it is these carbon-centered sugar radicals that lead to the most important types of DNA damage (e.g., $\mathrm{C}_{1^{\prime}}{ }^{\circ}$ sugar radical results in an abasic site), while, $\mathrm{C}_{3^{\prime}}{ }^{\circ}, \mathrm{C}_{4^{\prime}}$, and $\mathrm{C}_{5^{\prime}}{ }^{\circ}$ sugar radicals result in strand break formation $^{24,133-136}$ There are two principal mechanisms for the sugar radical formation: (i) the abstraction of a hydrogen atom from the sugar moiety by the hydroxyl radical $\left(\mathrm{OH}^{\bullet}\right)^{24,133-136}$ and (ii) direct ionization of sugar-phosphate backbone followed by rapid deprotonation. ${ }^{136}$ Recently, another mechanism of direct sugar radical formation from electronic excitation of one-electron-oxidized bases $\left(\mathrm{G}^{\bullet+}\right.$ and $\mathrm{A}^{\bullet+}$ ) was proposed. ${ }^{23-28,132,137,138}$ In this mechanism, ${ }^{23-28,132,137,138}$ shown in Scheme 1.1, photoexcitation induces hole transfer from $\mathrm{G}^{\bullet+}$ to the sugar ring, which is followed by a rapid deprotonation at specific carbon sites on the sugar ring. ${ }^{23-28,132,137,138}$

As indicated in the Introduction, this mechanism originated from the work with ion beam irradiations in which high concentrations of sugar radicals were formed 


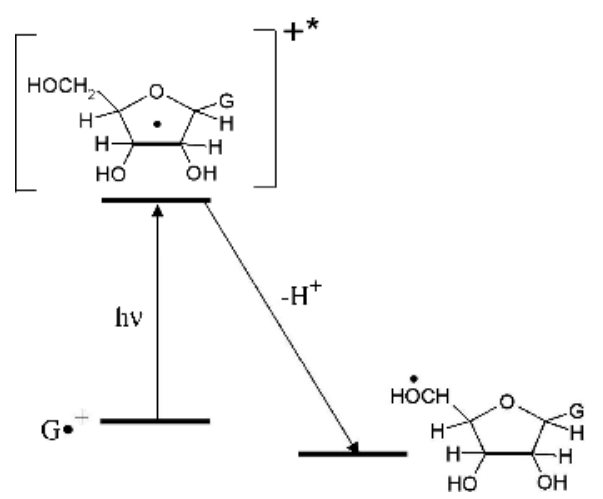

SCHEME 1.1. Proposed mechanism of the sugar radical formation (e.g., $\mathrm{C}_{5^{\prime}}$ ) via photoexcitation of $\mathrm{G}^{\bullet+}$. (Reprinted with permission from reference 138, J. Phys. Chem., copyright 2008 , American Chemical Society.)

predominantly along the ion track, where ionizations and excitations are in close proximity. The proposed hypothesis was experimentally verified using visible photoexcitation of $\mathrm{G}^{\bullet+}$ and $\mathrm{A}^{\bullet+}$ in DNA and a number of model systems of deoxyribonucleosides, dinucleoside phosphates, oligonucleotides, and RNA model systems and oligomers. ${ }^{24-28,137,138}$ In model systems, a high yield of conversion of $\mathrm{G}^{\bullet+}$ to sugar radical formation (80-100\%) was found, while with oligos of increasing length and DNA the yield was found to fall off to $\sim 50 \% .^{24,26,27}$ This experimental observation was further supported by theoretical calculations using time-dependent density functional theory. ${ }^{26-28}$ The excited states of $\mathrm{G}^{\bullet+26}$ and $\mathrm{A}(-\mathrm{H})^{\bullet 27}$ were studied using TD-B3LYP/6-31G* method, which clearly shows the all the transitions in the near-UV-visible range originate from the inner shell (core) molecular orbitals (MOs), and many of them involved base-to-sugar hole transfer ${ }^{26,27}$ as proposed in Scheme 1.1. The experimental studies were further extended to larger model systems such as dinucleoside phosphate TpdG cation radical, ${ }^{28}$ and the photoexcitation of $\mathrm{G}^{\bullet+}$ in TpdG radical cations resulted in $\sim 87 \%$ conversion of $\mathrm{G}^{\bullet+}$ to sugar radicals which were found to be located at the $\mathrm{C}_{1^{\prime}}$ and $\mathrm{C}_{3^{\prime}}$ sugar sites.

Theoretical studies of excited states of a number of dinucleoside phosphates, such as TpdG, dGpdG, dApdA, dApdT, TpdA, and dGpdT in their cationic radical states, were also performed using TD-B3LYP/6-31G(d) method to gain a better understanding of several aspects of photoinduced hole transfer within DNA. ${ }^{28,139}$ In these studies, the ground-state geometries of dinucleoside phosphates in their radical cation states were optimized in the B-DNA conformation at the B3LYP/6-31G(d) level of theory. ${ }^{28,139}$ The effect of solvation of the dinucleoside phosphate radical cations was considered through the polarized continuum model (PCM), and the vertical excitations energies were calculated using the TD-B3LYP/6-31G(d) method (for details see reference 139). For each case, the 20 lowest electronic transition energies, arising from the inner shell (core) molecular orbitals (MOs) to the singly occupied molecular orbital (SOMO) of $\beta$-spin, were calculated. ${ }^{28,139}$ It was found that the first electronic transition in every case involving hole transfer from base to base is a $\pi \rightarrow \pi^{*}$ 


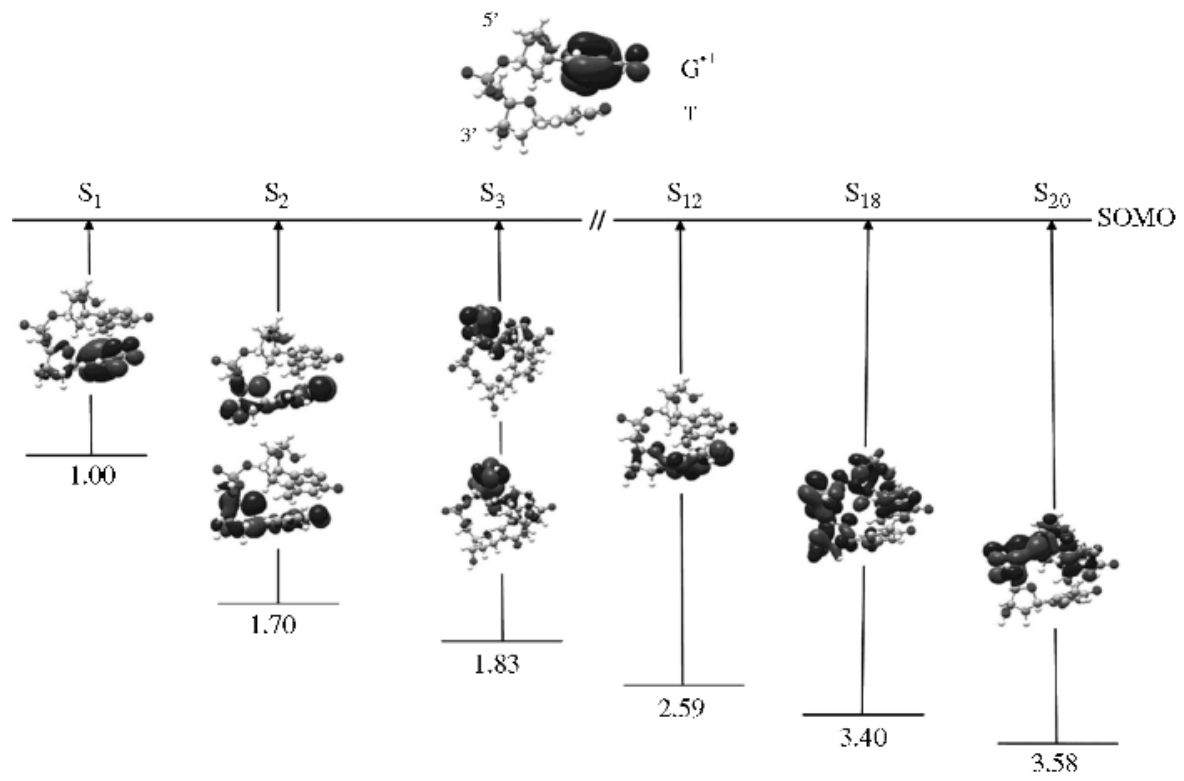

FIGURE 1.10. TD-B3LYP/6-31G(d)-computed transition energies of selected transitions of a dGpdT cation radical. Excitation energies are given in electron volts. (Reprinted with permission from reference 139, J. Phys. Chem., copyright 2006, American Chemical Society.)

transition. ${ }^{28,139}$ However, other higher-energy transitions involved hole transfer from base to sugar-phosphate region. In this context, an experimental wavelength-dependence study of sugar radical formation from $\mathrm{G}^{\bullet+}$ in $2^{\prime}$-deoxyguanosine (dGuo) and in DNA was also carried out by Adhikary et al. ${ }^{26}$ by varying the photoexcitation wavelength from visible to UV range. Interestingly they found that while in dGuo the sugar radical formation was independent of wavelength of light, the formation of sugar radicals in dsDNA only occurred below $540 \mathrm{~nm}^{26}$ Thus, the TD-DFT study ${ }^{28,139}$ clearly supports the experimental observations. ${ }^{26}$ As an example, in Figure 1.10, we present the selected transitions $S_{1}, S_{2}, S_{3}, S_{12}, S_{18}$, and $S_{20}$, which cover the visible to near-UV range for the $\mathrm{dGpdT}$ radical cation as calculated using the TD-B3LYP/6-31G(d) method. ${ }^{139}$ All six transitions are from core MOs to SOMO, and they are also shown in Figure 1.10.

From molecular orbital plots in Figure 1.10, we see that SOMO as well as SOMO-1 are localized on guanine and thymine rings in the dGpdT radical cation. Also, in Figure 1.10, the first three transitions $\left(\mathrm{S}_{1}-\mathrm{S}_{3}\right)$ correspond to the three lowest transitions, while the other three transitions $\left(\mathrm{S}_{12}, \mathrm{~S}_{18}\right.$, and $\left.\mathrm{S}_{20}\right)$ have been chosen which correspond to the dominant molecular orbital contribution from a single inner MO. From Figure 1.10, it is clearly evident that the first transition $\left(S_{1}\right)$ is $\pi \rightarrow \pi^{*}$ and involves the hole transfer from guanine to thymine (base-to-base) in $\mathrm{dG}^{\bullet+}$ pdT with a transition energy of $1.0 \mathrm{eV}$. However, the other transitions involve hole transfer from base to sugar ring and occur at higher energies $>1.7 \mathrm{eV}$. In this study, it was also found that the computed first transition $\left(\mathrm{S}_{1}\right)$ energy in all the cases was comparable to those 
calculated using the CAS-PT2 level of theory reported by Blancafort and Voityuk ${ }^{140}$ except for $(\mathrm{dApdA})^{\bullet+}$. The TD-B3LYP method is not suitable for long-range charge transfer excited states as pointed out by Head-Gordon and co-workers. ${ }^{141}$ However, a detailed analysis of transition energy calculation using an approximate approach ${ }^{141}$ clearly demonstrates that the TD-B3LYP method works quite well for this class of molecules (for details see reference 139). This is because hole migration is not equivalent to a charge transfer state in which charge separation occurs (hole and excess electron). Only in the latter case is coulombic interaction between the induced charges a factor. It is this interaction that is poorly treated by DFT, whereas for hole migration no such interaction exists.

\subsection{RADICALS AND TAUTOMERS OF DEPROTONATED GUANINE RADICAL CATION $\left(\mathbf{G}^{\cdot+}\right)$}

Guanine has the lowest ionization potential of the DNA bases, and for this reason it acts as a trap for the hole (positive charge) during oxidative processes on DNA such as ionization, followed by long-range hole transfer. It is well known that the acid and base properties of ionized bases (A, T, G, C, and U) are quite different from their corresponding neutral states ${ }^{58-61}$ (see Section 1.2.2), with anion radicals undergoing protonation and cation radicals undergoing deprotonation reactions. Thus, oneelectron-oxidized guanine $\left(\mathrm{G}^{\bullet+}\right)$ has a far lower $\mathrm{p} K_{a}$ value $(\sim 3.9)$ than its neutral guanine (9.0). ${ }^{58-61}$ Prototropic equilibria involving $\mathrm{G}^{\bullet+}$ in an aqueous environment (shown in Scheme 1.2) are therefore highly relevant to its subsequent chemistry.<smiles>[R]n1c([AsH2])nc2c(=O)[nH]c(N[Y19]#N)nc21</smiles><smiles></smiles>

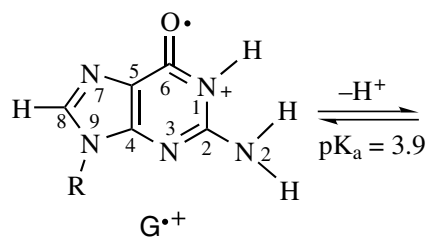

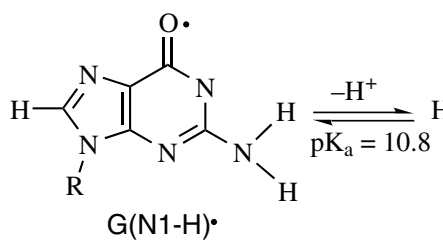<smiles></smiles>

SCHEME 1.2. The numbering scheme and prototropic equilibria of one-electron-oxidized guanine cation radical $\left(\mathrm{G}^{\bullet+}\right)$, the monodeprotonated species, $\mathrm{G}(\mathrm{N} 1-\mathrm{H})^{\bullet}$ and $\mathrm{G}(\mathrm{N} 2-\mathrm{H})^{\bullet}$, in synand anti-conformers with respect to the $\mathrm{N} 3$ atom and the dideprotonated species, $\left.\mathrm{G}(-2 \mathrm{H})^{\bullet-}\right)$. (Reprinted with permission from reference 157, J. Phys. Chem., copyright 2006), American Chemical Society.) 
Upon deprotonation of $\mathrm{G}^{\bullet+}$ (see Scheme 1.2), two isomeric radicals can form: (i) $\mathrm{G}(\mathrm{N} 1-\mathrm{H})^{\bullet}$ resulting from deprotonation from $\mathrm{N} 1$ and (ii) $\mathrm{G}(\mathrm{N} 2-\mathrm{H})^{\bullet}$ resulting from deprotonation from $\mathrm{N} 2$. Also, $\mathrm{G}(\mathrm{N} 1-\mathrm{H})^{\bullet}$ and $\mathrm{G}(\mathrm{N} 2-\mathrm{H})^{\bullet}$ (syn) have been suggested (from experiment) to be nearly isoenergetic because in aqueous environment the radical cations derived from $2^{\prime}$-deoxyguanosine $\left(\mathrm{dGuo}^{\circ}\right)$ and 1-methyl-2'-deoxyguanosine $\left(1 \mathrm{MedGuo}^{\circ+}\right)$ have similar $\mathrm{p} K_{a}$ values of 3.9 and 4.7 , respectively. ${ }^{142-144}$ Since N1 site in $1 \mathrm{MedGuo}^{\bullet+}$ is blocked by a methyl group, only G(N2-H) ${ }^{\bullet}$ forms upon deprotonation. ${ }^{144}$ Pulse radiolysis studies ${ }^{144-146}$ suggested the formation of G(N1-H) ${ }^{\bullet}$ without any specific evidence. At higher $\mathrm{pH}, \mathrm{G}(\mathrm{N} 1-\mathrm{H})^{\bullet}$ further deprotonates from $\mathrm{N} 2$ site, which gives $\mathrm{G}(-2 \mathrm{H})^{\bullet-}$ with a $\mathrm{p} K_{a}$ of $10.8^{144}$ (see Scheme 1.2). ENDOR studies of irradiated single crystals of guanine and their derivatives ${ }^{147,148}$ reported that $\mathrm{G}(\mathrm{N} 2-\mathrm{H})^{\bullet}$ was the species form by deprotonation. These experimental observations ${ }^{142-144}$ raised serious questions regarding the preferred site of deprotonation in $\mathrm{G}^{\bullet+}$. These questions have been treated by a number of authors employing both theory and experiment ${ }^{142-158}$ without definitive conclusions.

Recently, electron spin resonance (ESR) and the B3LYP/6-31G(d) level of theory have been used to identify the preferred site of deprotonation from guanine radical cation $\left(\mathrm{G}^{\cdot+}\right)$ in an aqueous medium at low temperatures as a function of $\mathrm{pH} .{ }^{157}$ In this study, ${ }^{157}$ the various species and their $\mathrm{pH}$ ranges were identified as $\mathrm{G}^{\bullet+}(\mathrm{pH} 3-5)$, $\mathrm{G}(-\mathrm{H})^{\bullet}(\mathrm{pH} 7-9)$ and $\mathrm{G}(-2 \mathrm{H})^{\bullet}(>11)$. To be able to draw a definite conclusion about the presence of a specific species, the geometries of all the structures shown in Scheme 1.2 were fully optimized using the B3LYP/6-31G(d) method ${ }^{157}$ in the presence of a single water molecule, placed near the $\mathrm{N} 1$ or $\mathrm{NH} 2$ sites of the molecule to compare the relative stabilities of these tautomers. The calculated relative stabilities of $\mathrm{G}(\mathrm{N} 1-\mathrm{H})^{\bullet}+\mathrm{H}_{2} \mathrm{O}, \mathrm{G}(\mathrm{N} 2-\mathrm{H})^{\bullet}($ syn $)+\mathrm{H}_{2} \mathrm{O}$ and $\mathrm{G}(\mathrm{N} 2-\mathrm{H})^{\bullet}($ anti $)+\mathrm{H}_{2} \mathrm{O}$ were found to be $2.65,0.0$, and $3.63 \mathrm{kcal} / \mathrm{mol},{ }^{157}$ respectively. These calculations therefore predict that $\mathrm{G}(\mathrm{N} 2-\mathrm{H})^{\bullet}(s y n)$ is the most stable species among all the three tautomers. Since a single water molecule was not enough to fully solvate the molecule, the relative stabilities were further calculated considering the effect of bulk solvent through polarized continuum model $(\mathrm{PCM})$, and again $\mathrm{G}(\mathrm{N} 2-\mathrm{H})^{\bullet}(s y n)+\mathrm{H}_{2} \mathrm{O}$ was found to be $\sim 1.00 \mathrm{kcal} / \mathrm{mol}$ more stable than $\mathrm{G}(\mathrm{N} 1-\mathrm{H})^{\bullet}+\mathrm{H}_{2} \mathrm{O} .{ }^{157}$ Using different theoretical models, ${ }^{152,154} \mathrm{G}(\mathrm{N} 2-\mathrm{H})^{\bullet}$ (syn) was found to be more stable than $\mathrm{G}(\mathrm{N} 1-\mathrm{H})^{\bullet}$ by $\sim 3.0-5.0 \mathrm{kcal} / \mathrm{mol}$. These theoretical calculations clearly predict the presence of $\mathrm{G}(\mathrm{N} 2-\mathrm{H})^{\bullet}($ syn $)$ species, but the B3LYP/6-31G(d) calculated hyperfine coupling constants (HFCCs) do match the ESR experimental HFCCs for single crystalline $\mathrm{dG}$ but not with those ESR experimental HFCCs found in solution. ${ }^{157}$

To rectify this problem, the theoretical model was further improved by including seven water molecules around the guanine base to consider the effect of the first hydration shell. ${ }^{157}$ The geometries of $\mathrm{G}^{\bullet+}+7 \mathrm{H}_{2} \mathrm{O}, \mathrm{G}(\mathrm{N} 1-\mathrm{H})^{\bullet}+7 \mathrm{H}_{2} \mathrm{O}$, and $\mathrm{G}(\mathrm{N} 2-\mathrm{H})^{\bullet}$ $($ syn $)+7 \mathrm{H}_{2} \mathrm{O}$ were fully optimized at the B3LYP/6-31G(d) level of theory. ${ }^{157}$ Interestingly, $\mathrm{G}(\mathrm{N} 1-\mathrm{H})^{\bullet}+7 \mathrm{H}_{2} \mathrm{O}$ was found to be more stable than the $\mathrm{G}(\mathrm{N} 2-\mathrm{H})^{\bullet}$ $($ syn $)+7 \mathrm{H}_{2} \mathrm{O}$ by $3.26 \mathrm{kcal} / \mathrm{mol}$; and using the $\mathrm{PCM}$ model, $\mathrm{G}(\mathrm{N} 1-\mathrm{H})^{\bullet}+7 \mathrm{H}_{2} \mathrm{O}$ was found to be still more stable than $\mathrm{G}(\mathrm{N} 2-\mathrm{H})^{\bullet}(s y n)+7 \mathrm{H}_{2} \mathrm{O}$ by $3.0 \mathrm{kcal} / \mathrm{mol} .{ }^{157}$ In this study, the strong hydrogen bonding between $\mathrm{G}(\mathrm{N} 1-\mathrm{H})^{\bullet}$ and seven water molecules was found to enhance the relative stability of $\mathrm{G}(\mathrm{N} 1-\mathrm{H})^{\bullet}$ tautomers on hydration. It was also 
noted that both the tautomers $\left(\mathrm{G}(\mathrm{N} 1-\mathrm{H})^{\bullet}\right.$ and $\mathrm{G}(\mathrm{N} 2-\mathrm{H})^{\bullet}($ syn $\left.)\right)$ had the same number of hydrogen bonds with the surrounding seven water molecules. Also, the B3LYP/6-31G (d)-calculated HFCCs for $\mathrm{G}^{\bullet+}+7 \mathrm{H}_{2} \mathrm{O}$ and $\mathrm{G}(\mathrm{N} 1-\mathrm{H})^{\bullet}+7 \mathrm{H}_{2} \mathrm{O}$ were found to be matched very well with the experimental ESR HFCCs. ${ }^{157}$ This study strongly supports the existence of the $\mathrm{G}(\mathrm{N} 1-\mathrm{H})^{\bullet}$ tautomer in the aqueous environment; and ${ }^{15} \mathrm{~N}$-substituted derivatives at $\mathrm{N} 1, \mathrm{~N} 2$, and N3 atoms in dGuo and C-8 deuteration of dGuo confirms that $\mathrm{N} 1-\mathrm{H}$ is the preferred site for deprotonation in an aqueous environment. Similar conclusions were also drawn by Naumov and Sonntag ${ }^{158}$ using UV-visible spectral properties and DFT study recently. Chatgilialoglu et al. ${ }^{155,156}$ also studied the tautomers of one-electron-oxidized guanosine using UV-visible spectral properties and the DFT method. Based on DFT results, they proposed the presence of a transient species $\mathrm{G}(\mathrm{N} 2-\mathrm{H})^{\bullet}($ syn $)$ which in the presence of a water molecule transfers proton from $\mathrm{N} 1$ to $\mathrm{N} 2$ and becomes $\mathrm{G}(\mathrm{N} 1-\mathrm{H})^{\bullet}$. Their calculated barrier height for the proton transfer using the B3LYP/6-31G* level of theory ${ }^{155}$ was found to be $18.8 \mathrm{~kJ} / \mathrm{mol}$. However, the same calculation was repeated in reference 157 using B3LYP/6-31G* method and barrier height was found to be $18.9 \mathrm{kcal} / \mathrm{mol}$, suggesting that units may have been incorrectly reported. Our work suggests that this transfer is not needed to produce $\mathrm{G}(\mathrm{N} 1-\mathrm{H})^{\bullet 155}$ because the low-energy pathway is found to be directly from N1.

\subsection{NATURE OF HOLE DELOCALIZATION IN ADENINE STACKS: THE DIMER RADICAL CATION $\left(\mathrm{A}_{2}\right)^{\bullet+}$}

The hole and electron transfer within DNA is of fundamental importance to many research and development areas such as radiation-induced DNA damage and repair, as well as DNA-based molecular devices and sensors. ${ }^{8,159,160}$ Also, while of fundamental significance, the mechanism of charge transfer in DNA is complex, involving both tunneling and hopping with modulation by environment or proton transfer reactions. Intra-base proton transfer in DNA plays a crucial role in controlling the charge transfer process in DNA. Such proton transfer reactions in DNA either slow or stop the charge transfer process in DNA. ${ }^{58,61,161-163}$ As already discussed in Sections 1.2.2 and 1.4, the proton transfer reactions will depend on the $\mathrm{p} K_{a}$ of the DNA bases. While the $\mathrm{p} K_{a}$ of the guanine radical cation is near 4 , the $\mathrm{p} K_{a}$ of adenine radical cation $\left(\mathrm{A}^{\bullet+}\right)$ produced from dAdo in aqueous solution was estimated by Steenken and co-workers ${ }^{58,61}$ to be $\leq$ 1 (a very strong acid). However, another study ${ }^{164}$ of the $\mathrm{pH}$ dependence of hole transfer from $\mathrm{A}^{\bullet+}$ to guanine in dinucleosides phosphate $\mathrm{ApG}$ and $\mathrm{GpA}^{164}$ suggested that the $\mathrm{p} K_{a}$ of $\mathrm{A}^{\bullet+}$ increase in these systems to $>1$. This result suggested an effect of base stacking on the $\mathrm{p}_{a}$ of $\mathrm{A}^{\bullet+}$. Many recent experiments ${ }^{165-169}$ have shown that stacked adenine bases provide a route to long-range hole transfer in DNA. This work finds that hole migration in DNA through several intervening adenines transfer with little distance dependence. These results seem inexplicable, given the known $\mathrm{p} K_{a}$ of the adenosine cation radical. Indeed the rate constants of hole transfer between adjacent adenines was experimentally determined in the range $10^{8}-10^{10} \mathrm{~s}^{-1},{ }^{166}$ which is slower than the proton $\left(\mathrm{H}^{+}\right)$transfer rate (estimated as $\left.<1 \mathrm{ps}\right){ }^{58}$ This suggests that 
deprotonation would occur before hole transfer and stop further hole transfer, which is contradictory to recent experiments. ${ }^{165-169}$ Since deprotonation of $\mathrm{A}^{\bullet+}$ would stop such transfer, these recent results suggest that the $\mathrm{p}_{a}$ for $\mathrm{A}^{\bullet+}$ in stacked DNA systems must be higher than for the isolated nucleoside in solution. In a study, Barton and coworkers ${ }^{169}$ proposed that in adenine stacks the hole is delocalized over several adenines. Very recently, the effects of base stacking on the acid-base properties of $\mathrm{A}^{\bullet+}$ were clarified by an investigation using electron spin resonance (ESR) and complementary DFT calculations. ${ }^{65}$

In this study, ${ }^{65} \mathrm{~A}^{\bullet+}$ was produced by one-electron oxidation of dAdo and the stacked DNA oligomer $(\mathrm{dA})_{6}$ by $\mathrm{Cl}_{2}{ }^{--}$in aqueous glass. Using ESR, the presence of $\mathrm{A}^{\bullet+}$ in dAdo was obtained in the $\mathrm{pH}$ range of 3-7, while in the $\mathrm{pH}$ range of 9-12 the presence of $\mathrm{A}(-\mathrm{H})^{\bullet}$ (deprotonated $\mathrm{A}^{\bullet+}$ ) was confirmed. As evident from Figure 1.11a, $\mathrm{A}^{\bullet+}$ and $\mathrm{A}(-\mathrm{H})^{\bullet}$ were found to be present in equal amounts at $\mathrm{pH} 8$ at $150 \mathrm{~K}$. This ESR study clearly shows that at $150 \mathrm{~K}, \mathrm{~A}^{\bullet+}$ has a $\mathrm{p} K_{a}$ value of 8 , which is quite different from the estimated $\mathrm{p} K_{a}(\leq 1)$ of $\mathrm{A}^{\bullet+}$ as estimated by Steenken. ${ }^{58}$ Furthermore, it is also well known that in an aqueous medium, dAdo tends to dimerize in the stacked conformation at ambient temperature ${ }^{170-173}$ having thermodynamic $\Delta \mathrm{G}^{0}, \Delta \mathrm{H}^{0}$, and $\Delta \mathrm{S}^{0}$ values as $-4.2 \mathrm{~kJ} \mathrm{~mol}^{-1},-27.2 \mathrm{~kJ} \mathrm{~mol}^{-1}$, and $-75.2 \mathrm{~J} \mathrm{~K}^{-1} \mathrm{~mol}^{-1}$, respectively. Based on these values, ${ }^{170-173}$ it is clear that $\mathrm{A}^{\bullet+}$ exists in stacked form in this lowtemperature aqueous glass. DFT calculations also show that an adenine radical cation dimer $\left(\mathrm{A}_{2}\right)^{\bullet+}$ is quite stable with a calculated $\mathrm{p} K_{a}$ of the dimer of 7 and that of the monomer of -0.3 (described below). Thus, the experimental $\mathrm{p} K_{a}$ value of 8 at $150 \mathrm{~K}$ was likely a result of base stacking, producing an adenine radical cation dimer or a

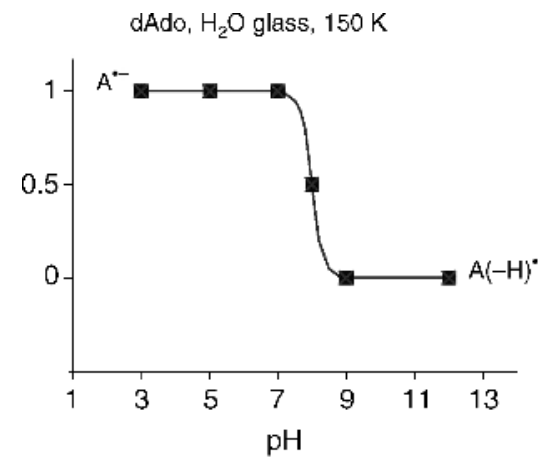

(a)

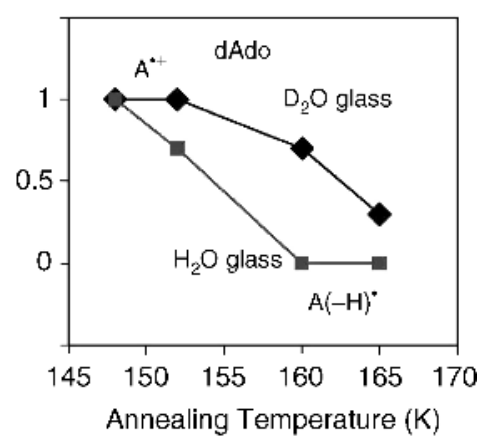

(b)

FIGURE 1.11. (a) The schematic diagram shows that $\mathrm{A}^{\bullet+}$ is found for $\mathrm{pHs}$ up to 7 and $\mathrm{A}(-\mathrm{H})^{\bullet}$ at $\mathrm{pHs}$ of 9 and above at $150 \mathrm{~K}$ in $7.5 \mathrm{M} \mathrm{LiCl} \mathrm{H}_{2} \mathrm{O}$ or $\mathrm{D}_{2} \mathrm{O}$ glasses. At $\mathrm{pH} 8$, equal amounts of $\mathrm{A}^{\bullet+}$ and $\mathrm{A}(-\mathrm{H})^{\bullet}$ are found; the $\mathrm{p} K_{a}$ of $\mathrm{A}^{\bullet+}$ is therefore $\sim 8$ at $150 \mathrm{~K}$ in these systems. In $\mathrm{D}_{2} \mathrm{O}$ glassy samples, the corresponding $\mathrm{p} K_{a}$ of $\mathrm{A}^{\cdot+}$ is $\sim 8.5$. (b) The prototropic equilibrium of $\mathrm{A}^{\cdot+}$ is found at $150 \mathrm{~K}$. However, annealing to a slightly higher temperature of $\sim 160 \mathrm{~K}$ and above allows for molecular migration, and deprotonation is found at all pHs investigated (i.e., 3-12) in $\mathrm{H}_{2} \mathrm{O}$ glasses. In $\mathrm{D}_{2} \mathrm{O}$ glasses, which soften at slightly higher temperatures, deprotonation of $\mathrm{A}^{\bullet+}$ is nearly complete at $165 \mathrm{~K}$. (Reprinted with permission from reference 65, J. Am. Chem. Soc., copyright (2008 American Chemical Society.) 
higher multimer. At high annealing temperatures at $160 \mathrm{~K}$ in $\mathrm{H}_{2} \mathrm{O}$ glass, this dimer breaks apart into monomer $\mathrm{A}^{\bullet+}$ and deprotonates spontaneously to yield $\mathrm{A}(-\mathrm{H}){ }^{\bullet}$ as found by Steenken ${ }^{58}$ and shown in Figure 1.11b. Similar behavior of $A^{\cdot+}$ in stacked oligomers $(\mathrm{dA})_{6}{ }^{174}$ was found at $160 \mathrm{~K}^{65}$

To better understand the nature of hole delocalization in the stacked adenine dimer, theoretical calculations were performed using B3LYP, MP2, BHandHLYP, MPWB95, and the $6-31 \mathrm{G}^{*}$ basis set. The geometries of adenine $(\mathrm{A})$, adenine radical cation $\left(\mathrm{A}^{\bullet+}\right)$, syn- and anti-adenine radical (deprotonated at $\mathrm{NH}_{2}$ group, see Figure 1.1 for syn- and anti- convention with reference to $\mathrm{N} 1$ atom), adenine dimer $\left(\mathrm{A}_{\mathrm{B}}-\mathrm{A}_{\mathrm{B}}\right)_{\mathrm{s}}$, and adenine dimer radical cation $\left(\left(A_{B}-A_{B}\right)_{s}{ }^{*+}\right)$ in stacked conformations were fully optimized. Furthermore, to see the effect of an aqueous environment, the geometries of adenine radical cation $\left(\mathrm{A}^{\bullet+}\right)$ and $\left(\left(\mathrm{A}_{\mathrm{B}}-\mathrm{A}_{\mathrm{B}}\right)_{\mathrm{s}}{ }^{\cdot+}\right)$ were fully optimized in the presence of 7 and 18 water molecules and designated as $\mathrm{A}^{\cdot+}+7 \mathrm{H}_{2} \mathrm{O}$ and $\left(\mathrm{A}_{\mathrm{B}}-\mathrm{A}_{\mathrm{B}}\right)_{\mathrm{s}}{ }^{\cdot+}+18 \mathrm{H}_{2} \mathrm{O}$. Here $\mathrm{A}$ and $A_{B}$ refer to dAdo (see Figure 1.4) and adenine base molecule, respectively (for a complete description, see reference 65).

As mentioned in Section 1.2.2 and shown in Figure 1.4, the $\mathrm{p}_{a}$ of $\mathrm{A}^{\cdot+}$ was calculated using the B3LYP/6-31G* (PCM) method and was found to be -0.3 . The $\mathrm{B} 3 \mathrm{LYP} / 6-31 \mathrm{G}^{*}$ calculation of $\mathrm{A}^{\bullet+}$ in the presence of a solvent environment $\left(\mathrm{A}^{\bullet+}+7 \mathrm{H}_{2} \mathrm{O}\right)$ found that deprotonation from an $\mathrm{NH}_{2}$ group occurs without a significant barrier (see Figure 1.4). This clearly shows the strongly acidic nature of $\mathrm{A}^{\bullet+}$ reported previously for the monomer in aqueous solution. Furthermore, the $\mathrm{p} K_{a}$ of $\left(A_{B}-A_{B}\right)_{s}{ }^{++}$was also calculated at the same level of theory. Initially, the geometry of $\left(A_{B}-A_{B}\right)_{s}^{\cdot+}$ was fully optimized in the Cs symmetry using the B3LYP/6-31G* method, and it was found that $\left(A_{B}-A_{B}\right)_{s}{ }^{\cdot+}$ was stabilized by $-12.08 \mathrm{kcal} / \mathrm{mol}$ (basis set superposition error (BSSE) corrected). Since the B3LYP method is not suitable for estimation of stacking energies in stacked neutral systems (dispersion is not treated well), the calculations were further improved using the MP2 level of theory; and the BSSE-corrected stabilization energy was found to be $-15.64 \mathrm{kcal} / \mathrm{mol}$. This suggests the applicability of the B3LYP method for this class of molecules, stacked dimer cation radicals, in which the binding is a charge resonance interaction. Thus after this verification of the computational level, the B3LYP/6-31G*-calculated $\mathrm{p} K_{a}$ value of $\left(A_{B}-A_{B}\right)_{s}{ }^{++}$was performed and found to be 7 , which is in close agreement with the estimated value of 8 (see Figure 1.11). Thus these theoretical calculations show the substantial binding interactions in stacked adenines such as the adenine radical cation $\operatorname{dimer}\left(\mathrm{A}_{2}\right)^{\bullet+}$.

The geometry of $\left(\mathrm{A}_{\mathrm{B}}-\mathrm{A}_{\mathrm{B}}\right)_{\mathrm{s}}{ }^{\cdot+}+18 \mathrm{H}_{2} \mathrm{O}$ was fully optimized at the B3LYP/6-31G* level of theory, and the potential energy surface (PES) for the stretching of $\mathrm{N}-\mathrm{H}$ bond was calculated starting from the equilibrium $\mathrm{N}-\mathrm{H}$ bond length to $1.45 \AA$ in the step size of $0.05 \AA$. The same calculation was done for $\mathrm{A}^{\cdot+}+7 \mathrm{H}_{2} \mathrm{O}$. The PESs of $\mathrm{N}-\mathrm{H}$ bond stretching in $\mathrm{A}^{\cdot+}+7 \mathrm{H}_{2} \mathrm{O}$ and of $\left(\mathrm{A}_{\mathrm{B}}-\mathrm{A}_{\mathrm{B}}\right)_{\mathrm{s}}{ }^{\cdot+}+18 \mathrm{H}_{2} \mathrm{O}$ are shown in Figure 1.12. In contrast to the $\mathrm{A}^{\cdot+}+7 \mathrm{H}_{2} \mathrm{O}$ which showed no barrier to deprotonation, it is found that the barrier height for $\left(\mathrm{A}_{\mathrm{B}}-\mathrm{A}_{\mathrm{B}}\right)_{\mathrm{s}}{ }^{+}+18 \mathrm{H}_{2} \mathrm{O}$ increased with an increase of $\mathrm{N}-\mathrm{H}$ bond length, showing a clear uphill process. This supports the high $\mathrm{p} K_{a}$ value of $\mathrm{A}^{\bullet+}$ in stacked dimer conformation as estimated by the present experiment and calculations. ${ }^{65}$ 


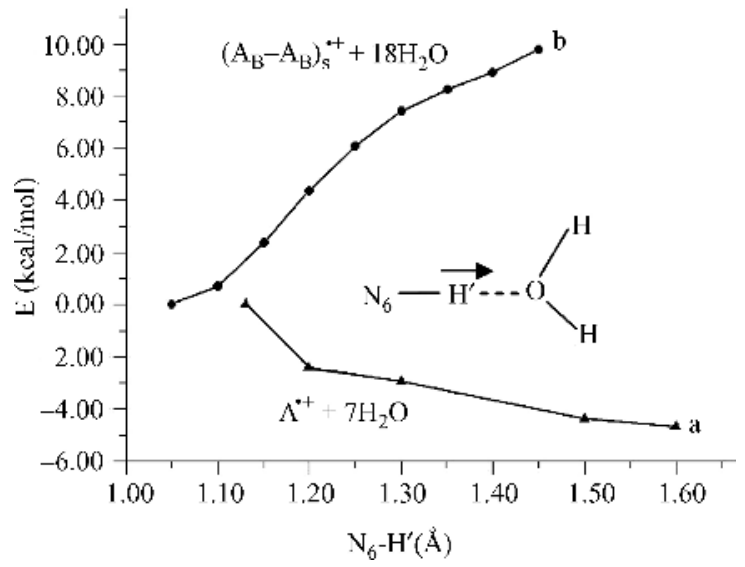

FIGURE 1.12. Potential energy surface (PES) of $\mathrm{N}_{6}-\mathrm{H}^{\prime}$ bond dissociation of (a) $\mathrm{A}^{\bullet+}+7 \mathrm{H}_{2} \mathrm{O}$ cation radical and $(\mathbf{b})\left(\mathrm{A}_{\mathrm{B}}-\mathrm{A}_{\mathrm{B}}\right)_{\mathrm{s}}{ }^{++}+18 \mathrm{H}_{2} \mathrm{O}$ cation radical in stacked conformation. The distances and energies are given in angstroms (A) and $\mathrm{kcal} / \mathrm{mol}$, respectively. See Figures1.4 and 1.13 for structures. (Reprinted with permission from reference 65, J. Am. Chem. Soc., copyright 2008, American Chemical Society.)

After obtaining a very good match between theory and experiment ${ }^{65}$ of $\mathrm{p} K_{a}$ values, the spin density distributions in adenine dimer radical cation $\left[\left(A_{B}-A_{B}\right)_{s}^{\bullet+}\right]$ in gas phase and in the presence of 18 water molecules were calculated using the B3LYP/6$31 \mathrm{G}^{*}$ method. From the spin density distributions, it was found that spin densities were equally distributed on both of the adenine rings in $\left(A_{B}-A_{B}\right)_{s}{ }^{+}$(see Figure 1.13a), while in the presence of waters the spin density is more localized on one of the adenine rings (73\%; see Figure 1.13b). It appears that on optimization, the relaxation of the surrounding water molecules tend to stabilize the hole (spin density) more on one of the adenine rings (see the upper adenine ring in Figure 1.13b). The B3LYP method is known to overestimate delocalization as a result of the self-interaction error, particularly, for odd electron containing molecular systems. ${ }^{175}$ Therefore, the spin densities were also calculated using the HF/6-31G* method considering the B3LYP/6-31G* generated geometries. The $\mathrm{HF} / 6-31 \mathrm{G}^{*}$ method also shows the delocalization of spin density on both of the adenine rings in $\left(A_{B}-A_{B}\right)_{s}{ }^{+}$and localization of more spin density on one of the adenine ring in $\left(\mathrm{A}_{\mathrm{B}}-\mathrm{A}_{\mathrm{B}}\right)_{\mathrm{s}}{ }^{+}+18 \mathrm{H}_{2} \mathrm{O}$ as obtained with B3LYP method, see Figures $1.13 \mathrm{c}$ and $1.13 \mathrm{~d}$.

These results clearly indicate the peculiar behavior of adenine radical cation $\left(\mathrm{A}^{\bullet+}\right)$ in stacks of adenines that is quite different than the behavior of the guanine radical cation in guanine stacks where hole localization is found. In this context, the singly occupied molecular orbital (SOMO) of $\mathrm{dG}^{\bullet+} \mathrm{pdG},(\mathrm{dApdA})^{\bullet+}$ and $\mathrm{dA}(-\mathrm{H})^{\bullet} \mathrm{pdA}$ were calculated using the B3LYP/6-31G* method. ${ }^{139}$ From Figure $1.14 \mathrm{a}$, it is evident that in $\mathrm{dG}^{\bullet+} \mathrm{pdG}, \mathrm{SOMO}$ is localized on one of the guanines (84\% spin density) at the $5^{\prime}$ end. In the $(\mathrm{dApdA})^{\bullet+}$ the SOMO is equally delocalized on both of the adenine rings (Figure 1.14b), while in the deprotonated $\mathrm{dA}(-\mathrm{H})^{\circ} \mathrm{pdA}$ the spin density is totally localized on the $\mathrm{A}(-\mathrm{H})$ adenine ring as expected (Figure 1.14c). This study shows that 


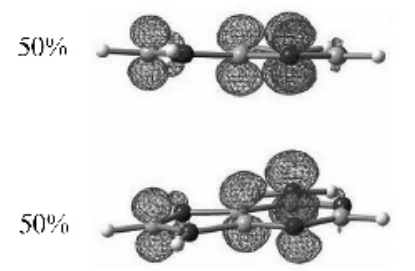

(a)

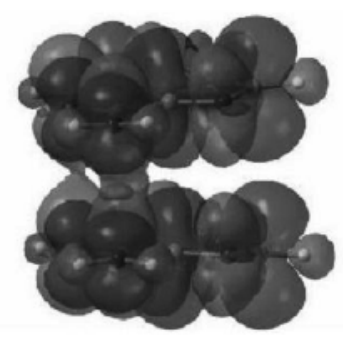

(c)

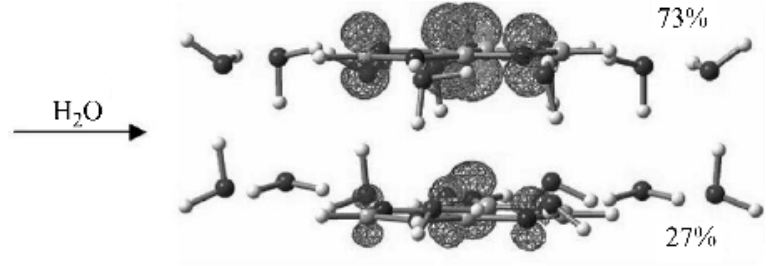

(b)

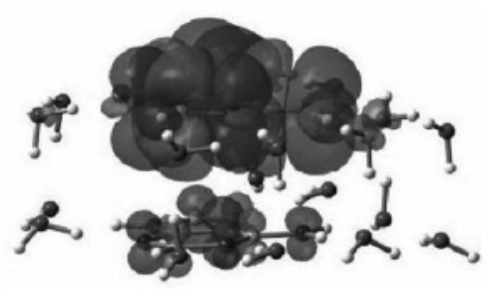

(d)

FIGURE 1.13. B3LYP/6-31G* calculated spin-density distribution shown in percentages in (a) the base-stacked adenine dimer cation radical $\left[\left(\mathrm{A}_{\mathrm{B}}-\mathrm{A}_{\mathrm{B}}\right)_{\mathrm{s}}{ }^{\cdot+}\right]$ in gas phase and $(\mathbf{b})$ the basestacked adenine dimer cation radical surrounded by 18 water molecules. On optimization, the water molecules adjust to favor spin on one of the adenine rings in $\left[\left(\mathrm{A}_{\mathrm{B}}-\mathrm{A}_{\mathrm{B}}\right)_{\mathrm{s}}^{\cdot+}+18 \mathrm{H}_{2} \mathrm{O}\right]$ complex. (c) and (d) are the HF/6-31G*//B3LYP/6-31G* calculated spin-density distributions of systems shown in parts a and $\mathrm{b}$, respectively. (Reprinted with permission from reference 65 , J. Am. Chem. Soc., copyright 2008, American Chemical Society.)

in $\mathrm{dG}^{\bullet+} \mathrm{pdG}$ the hole is localized; however, in $(\mathrm{dApdA})^{\bullet+}$ the hole tends to be delocalized.

This study ${ }^{65}$ also shows that the hole delocalization over the dimer cation resulted in substantial energy stabilization. For example, in comparison to the neutral adenine dimer which showed only weak interactions of a few kilocalories, $\left(\mathrm{A}_{2}\right)^{\bullet+}$ was found to have a high binding energy of $12-16 \mathrm{kcal} / \mathrm{mol}$ depending on the level of calculation (see details in reference 65). As already mentioned in Section 1.2.1, the nuclear

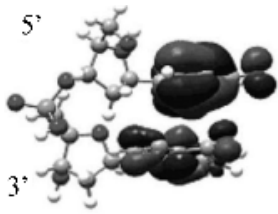

(a)

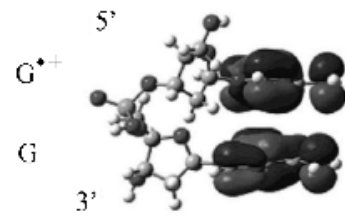

(b)

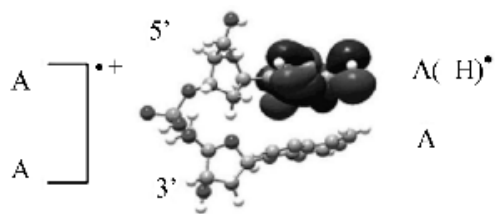

(c)

FIGURE 1.14. B3LYP/6-31G* calculated singly occupied molecular orbital (SOMO) plots of (a) $\mathrm{dG}^{\bullet+} \mathrm{pdG},(\mathbf{b})(\mathrm{dApdA})^{\bullet+}$, and (c) $\mathrm{dA}(-\mathrm{H})^{\bullet}$ pdA. (Reprinted with permission from reference 139, J. Phys. Chem., copyright 2006 American Chemical Society.) 
relaxation energy (NRE) of $\mathrm{A}, \mathrm{T}, \mathrm{G}, \mathrm{C}$, and $\mathrm{U}$ are experimentally estimated from the difference between their corresponding adiabatic and vertical ionization potential values (see Table 1.1). Among all the bases, adenine has the lowest NRE $(0.18 \mathrm{eV})$ and guanine has the largest NRE $(0.47 \mathrm{eV})$. These NRE values show that the geometrical change in adenine radical cation in comparison to neutral adenine is modest, while the geometrical change in guanine radical cation in comparison to neutral guanine is substantial. Calculations also predicted a very small NRE $(0.1 \mathrm{eV})$ of adenine radical formation in the AT base pair; however, the corresponding value for the guanine radical cation in the GC base pair was found to be $0.3 \mathrm{eV}{ }^{48,49}$ Thus, adenine radical cation $\left(\mathrm{A}^{\bullet+}\right)$ has almost the same structure as it has in the neutral state. Thus in the DNA, adenine stack tends to delocalize the hole, while guanine stack tends to localize as a result of the large nuclear relaxation for $\mathrm{G}^{\bullet+}$. Blancafort and Voityuk ${ }^{140}$ calculated the transition energy of $\mathrm{A}^{\bullet+} \mathrm{A}$ using the CAS-PT2 $(11,12)$ level of theory and found a very small first transition energy $0.1 \mathrm{eV}$, and they assumed this small transition energy to be a problem in choosing the active space. But now it is clear from this study ${ }^{65}$ that this small transition energy $(0.1 \mathrm{eV})$ was due to hole delocalization on both the adenine rings. The B3LYP/6-31G* calculated transition energy $(0.5 \mathrm{eV})$ of $(\mathrm{dApdA})^{\bullet+}$ was also found to be smallest among all the considered dinucleoside radical cations ${ }^{139}$ because the hole in this case only was found to be delocalized (see Figure 1.14b).

\subsection{CONCLUSIONS}

The wide applications of theory to the studies of DNA radiation damage summarized in this review show that this area is of substantial and growing interest. Many successful theoretical studies have elucidated the detailed mechanisms that help to explain experiment. The agreement between theory and experiment is expected to improve as the theoretical model better mimics the experimental situation. With everincreasing computing power and recent advances in theory, theory can be applied to more complex problems. For example, DFT is now used routinely for large molecular systems, even for substantial sections of DNA. DFT, especially with B3LYP, inherently has a number of limitations such as the self-interaction error that overestimates spin delocalization, the poor accounting for the coulombic term in charge transfer states, and poor treatment of dispersion interactions essential for DNA stacking. However, each of these problems is being treated, and progress is being made in corrections with new functionals. For example, recently, the development of new functionals in DFT has been found to be very suitable to study noncovalent and stacking interactions. Time-dependent density functional theory (TD-DFT) is found quite successful to describe the excited state properties of ionized DNA bases and base pairs. Furthermore, the DFT delocalization problem has been dealt with by functionals that increase the HF exchange contribution such as BH\&HLYP which has a $50 \% \mathrm{HF}$ exchange contribution. Thus such DFT calculations of hole delocalization in adenine stacks have led to a new understanding of hole transfer through adenine stacks within DNA. 


\section{ACKNOWLEDGMENTS}

This work was supported by the NIH NCI under Grant R01CA045424. The authors are also grateful to the Arctic Region Supercomputing Center (ARSC) for generously providing the computational time to perform some of these calculations. Computational studies were also supported by a computational facilities grant NSF CHE-0722689.

\section{REFERENCES}

1. Sevilla, M. D.; Becker, D. ESR studies of radiation damage to DNA and related biomolecules. In Royal Society of Chemistry Special Periodical Report, Vol. 19, Electron spin resonance, London, 2004, p. 243.

2. Becker, D.; Sevilla, M. D. The chemical consequences of radiation damage to DNA. In Advances in Radiation Biology, Vol. 17; Lett, J., ed.; Academic Press, New York, 1993, p. 121.

3. Burrows, C. J.; Muller, J. G. Oxidative nucleobase modifications leading to strand scission. Chem. Rev. 1998, 98, 1109-1152.

4. von Sonntag C. The chemistry of free-radical-mediated DNA damage. In Physical and Chemical Mechanisms in Molecular Radiation Biology; Glass, W. A.; Varma, M. N., Eds.; Plenum, New York, 1991, p. 287.

5. Swarts, S. G.; Sevilla, M. D.; Becker, D.; Tokar, C. J.; Wheeler, K. T. Radiation-induced DNA damage as a function of hydration. I. Release of unaltered bases. Radiat. Res. 1992, 129, 333-344.

6. Swiderek, P. Fundamental processes in radiation damage of DNA. Angew. Chem. Int. Ed. 2006, 45, 4056-4059.

7. Xifeng, L.; Sevilla, M. D. DFT treatment of radiation produced radicals in DNA model systems. Adv. Quantum Chem. 2007, 52, 59-87.

8. Becker, D.; Adhikary, A.; Sevilla, M. D. The role of charge and spin migration in DNA radiation damage. In Charge Migration in DNA; Chakraborty, T.,Ed.; Springer-Verlag, Berlin, 2007; pp. 139-175.

9. Kumar, A.; Sevilla M.D. Radiation effects on DNA: Theoretical investigations of electron, hole and excitation pathways to DNA damage. In Radiation Induced Molecular Phenomena in Nucleic Acid: A Comprehensive Theoretical and Experimental Analysis; Shukla, M. K.; Leszczynski, J.,Eds.; Springer-Verlag, Berlin, 2008, pp. 577-617.

10. Sevilla, M. D.; Bernhard, W. A. Mechanisms of direct radiation damage to DNA. In Radiation Chemistry from Basics to Applications in Material and Life Sciences; Spotheim-Maurizot, M.; Mostafavi, M.; Douki, T.; Belloni, J.,Eds.; EDP Sciences, Cedex A, France, 2008; pp. 191-201.

11. Hanel, G.; Gstir, B.; Denifl, S.; Scheier, P.; Probst, M.; Farizon, B.; Farizon, M.; Illenberger, E.; Märk, T. D. Electron attachment to uracil: Effective destruction at subexcitation energies. Phys. Rev. Lett. 2003, 90, 188-104.

12. Boudaïffa, B.; Cloutier, P.; Hunting, D.; Huels, M. A.; Sanche, L. Resonant formation of DNA strand breaks by low-energy (3 to $20 \mathrm{eV}$ ) electrons. Science 2000, 287, 1658-1660. 
13. Huels, M. A.; Boudaïffa, B.; Cloutier, P.; Hunting, D.; Sanche, L. Single, double, and multiple double strand breaks induced in DNA by 3-100 eV electrons. J. Am. Chem. Soc. 2003, 125, 4467-4477.

14. Sanche, L. Low energy electron-driven damage in biomolecules. Eur. Phys. J. D. 2005, 35, 367-390.

15. Zheng, Y.; Cloutier, P.; Hunting, D. J.; Sanche, L.; Wagner, J. R. Chemical basis of DNA sugar-phosphate cleavage by low-energy electrons. J. Am. Chem. Soc. 2005, 127, 16592-16598.

16. Zheng, Y.; Wagner, J. R.; Sanche, L. DNA damage induced by low-energy electrons: Electron transfer and diffraction. Phys. Rev. Lett. 2006, 96, 208-101.

17. Ptasińska, S.; Sanche, L. Dissociative electron attachment to hydrated single DNA strands. Phys. Rev. E 2007, 75, 031915.

18. Ptasińska, S.; Sanche, L. Dissociative electron attachment to abasic DNA. Phys. Chem. Chem. Phys. 2007, 9, 1730-1735.

19. Baccarelli, I.; Gianturco, F. A.; Grandi, A.; Sanna, N. Lucchese, R. R.; Bald, I.; Kopyra, J.; Illenberger, E. Selective bond breaking in $\beta$-D-ribose by gas-phase electron attachment around 8 eV. J. Am. Chem. Soc. 2007, 129, 6269-6277.

20. Sulzer, P.; Ptasińska, S.; Zappa, F.; Mielewska, B.; Milosavljevic, A. R.; Scheier, P.; Märk, T. D.; Bald, I.; Gohlke, S.; Huels, M. A., Illenberger, E. Dissociative electron attachment to furan, tetrahydrofuran, and fructose. J. Chem. Phys. 2006, 125, 044304.

21. Bald, I.; Kopyra, J.; Illenberger, E. Selective excision of C5 from D-ribose in the gas phase by low-energy electrons $(0-1 \mathrm{eV})$ : Implications for the mechanism of DNA damage. Angew. Chem., Int. Ed. 2006, 45, 4851-4855.

22. König, C.; Kopyra, J.; Bald, I.; Illenberger, E. Dissociative electron attachment to phosphoric acid esters: The direct mechanism for single strand breaks in DNA. Phys. Rev. Lett. 2006, 97, 018105.

23. Becker, D.; Bryant-Friedrich, A.; Trzasko, C.; Sevilla, M. D. Electron spin resonance study of DNA irradiated with an argon-ion beam: Evidence for formation of sugar phosphate backbone radicals. Radiat. Res. 2003, 160, 174-185

24. Shukla, L. I.; Pazdro, R.; Huang, J.; DeVreugd, C.; Becker, D.; Sevilla, M. D. The formation of DNA sugar radicals from photoexcitation of guanine cation radicals. Radiat. Res. 2004, 161, 582-590.

25. Shukla, L. I.; Pazdro, R.; Becker, D.; Sevilla, M. D. Sugar radicals in DNA: Isolation of neutral radicals in gamma-irradiated DNA by hole and electron scavenging. Radiat. Res. 2005, 163, 591-602.

26. Adhikary, A.; Malkhasian, A. Y. S.; Collins, S.; Koppen, J.; Becker, D.; Sevilla, M. D. UVA-visible photo-excitation of guanine radical cations produces sugar radicals in DNA and model structures. Nucleic Acids Res. 2005, 33, 5553-5564.

27. Adhikary, A.; Collins, S.; Koppen, J.; Becker, D.; Sevilla, M. D. C5'- and C3'-sugar radicals produced via photo-excitation of one-electron oxidized adenine in $2^{\prime}$-deoxyadenosine and its derivatives. Nucleic Acid Res. 2006, 34, 1501-1511.

28. Adhikary, A.; Kumar, A.; Sevilla, M. D. Photo-induced hole transfer from base to sugar in DNA: Relationship to primary radiation damage. Radiat. Res. 2006, 165, 479-484.

29. Baker, J.; Wolinski, K.; Malagoli, M.; Kinghorn, D.; Wolinski, P.; Magyarfalvi, G.; Saebo, S.; Janowski, T.; Pulay, P. Quantum chemistry in parallel with PQS. J. Comput. Chem. 2009, 30, 317-335. 
30. Sevilla, M. D.; Becker, D.; Yan, M.; Summerfield, S. R. Relative abundances of primary ion radicals in $\gamma$-irradiated DNA: Cytosine vs thymine anions and guanine vs adenine cations J. Phys. Chem. 1991, 95, 3409-3415.

31. Hush, N. S.; Cheung, A. S. Ionization potentials and donor properties of nucleic acid bases and related compounds. Chem. Phys. Lett. 1975, 34, 11-13.

32. Orlov, V. M.; Smirnov, A. N.; Varshavsky, Y. M. Ionization potentials and electrondonor ability of nucleic acid bases and their analogues. Tetrahedron Lett. 1976, 17, 4315-4394.

33. Choi, K.-W.; Lee, J.-H.; Kim, S. K. Ionization spectroscopy of a DNA base: Vacuumultraviolet mass-analyzed threshold ionization spectroscopy of jet-cooled thymine. $J$. Am. Chem. Soc. 2005, 127, 15674-15675.

34. Sevilla, M. D.; Besler, B.; Colson, A. O. Ab initio molecular orbital calculations of DNA radical ions. 5. Scaling of calculated electron affinities and ionization potentials to experimental values. J. Phys. Chem. 1995, 99, 1060-1063.

35. Russo, N.; Toscano, M.; Grand, A. Theoretical determination of electron affinity and ionization potential of DNA and RNA bases. J. Comput. Chem. 2000, 21, 1243-1250.

36. Wetmore, S. D.; Boyd, R. J.; Eriksson, L. A. Electron affinities and ionization potentials of nucleotide bases. Chem. Phys. Lett. 2000, 322, 129-135.

37. Rubio, M.; Roca-Sanjuán, D.; Merchán, M.; Serrano-Andrés, L. Determination of the lowest-energy oxidation site in nucleotides: $2^{\prime}$-Deoxythymidine $5^{\prime}$-monophosphate anion. J. Phys. Chem. B 2006, 110, 10234-10235.

38. Tureček, F. Computational studies of radicals relevant to nucleic acid damage. $A d v$. Quantum Chem. 2007, 52, 89-120.

39. Cauët, E.; Dehareng D.; Liévin, J. Ab initio study of the ionization of the DNA bases: Ionization potentials and excited states of the cations. J. Phys. Chem. A 2006, 110, 9200-9211.

40. Crespo-Hernandez, C. E.; Arce, R.; Ishikawa, Y.; Gorb, L.; Leszczynski, J.; Close, D. M. $\mathrm{Ab}$ initio ionization energy thresholds of DNA and RNA bases in gas phase and in aqueous solution. J. Phys. Chem. A 2004, 108, 6373-6377.

41. Zakjevskii, V. V.; King, S. J.; Dolgounitcheva, O.; Zakrzewski, V. G.; Ortiz, J. V. Base and phosphate electron detachment energies of deoxyribonucleotide anions. J. Am. Chem. Soc. 2006, 128, 13350-13351.

42. Yang, X.; Wang, X.-B.; Vorpagel, E. R.; Wang, L.-S. Direct experimental observation of the low ionization potentials of guanine in free oligonucleotides by using photoelectron spectroscopy. Proc. Natl. Acad. Sci. USA 2004, 101, 17588-17592.

43. Fernando, H.; Papadantonakis, G. A.; Kim, N. S.; Lebreton, P. R. Conduction-band-edge ionization thresholds of DNA components in aqueous solution. Proc. Natl. Acad. Sci. USA 1998, 95, 5550-5555.

44. Colson, A. O.; Besler, B.; Sevilla, M. D. Ab initio molecular orbital calculations on DNA radical ions. 3. Ionization potentials and ionization sites in components of the DNA sugar phosphate backbone. J. Phys. Chem. 1993, 97, 8092-8097.

45. Kim, S. K.; Lee, W.; Herschbach, D. R. Cluster beam chemistry: Hydration of nucleic acid bases; ionization potentials of hydrated adenine and thymine. J. Phys. Chem. 1996, 100, 7933-7937.

46. Close, D. M. Calculation of the ionization potentials of the DNA bases in aqueous medium. J. Phys. Chem. A 2004, 108, 10376-10379. 
47. Colson, A. O.; Besler, B.; Sevilla, M. D. Ab initio molecular orbital calculations on DNA base pair radical ions: Effect of base pairing on proton-transfer energies, electron affinities, and ionization potentials. J. Phys. Chem. 1992, 96, 9787-9794.

48. Li, X. F.; Cai, Z. L.; Sevilla, M. D. Energetics of the radical ions of the AT and AU base pairs: A density functional theory (DFT) study. J. Phys. Chem. A 2002, 106, 9345-9351.

49. Li, X. F.; Cai, Z. L.; Sevilla, M. D. Investigation of proton transfer within DNA base pair anion and cation radicals by density functional theory (DFT). J. Phys. Chem. B 2001, 105, 10115-10123.

50. Hutter, M.; Clark, T. On the enhanced stability of the guanine-cytosine base-pair radical cation. J. Am. Chem. Soc. 1996, 118, 7574-7577.

51. Bertran, J.; Oliva, A.; Rodriguez-Santiago, L.; Sodupe, M. Single versus double protontransfer reactions in Watson-Crick base pair radical cations. A theoretical study. J. Am. Chem. Soc. 1998, 120, 8159-8167.

52. Colson, A. O.; Sevilla, M. D. Elucidation of primary radiation-damage in DNA through application of ab-initio molecular-orbital theory. Int. J. Radiat. Biol. 1995, 67, 627-645.

53. Colson, A. O.; Besler, B.; Sevilla, M. D. Ab-initio molecular-orbital calculations an DNA radical ions. 4. Effect of hydration an electron-affinities and ionization-potentials of basepairs. J. Phys. Chem. 1993, 97, 13852-13859.

54. Barnett, R. N.; Cleveland, C. L.; Joy, A.; Landman, U.; Schuster, G. B. Charge migration in DNA: Ion-gated transport. Science 2001, 294, 567-571.

55. Hutter, M. C. Stability of the guanine-cytosine radical cation in DNA base pairs triplets. Chem. Phys. 2006, 326, 240-245.

56. Prat, F.; Houk, K. N.; Foote, C. S. Effect of guanine stacking on the oxidation of 8oxoguanine in B-DNA. J. Am. Chem. Soc. 1998, 120, 845-846.

57. Sugiyama, H.; Saito, I. Theoretical studies of GG-specific photocleavage of DNA via electron transfer: Significant lowering of ionization potential and 5'-localization of HOMO of stacked GG bases in B-form DNA. J. Am. Chem. Soc. 1996, 118, 7063-7068.

58. Steenken, S. Purine bases, nucleosides, and nucleotides: Aqueous solution redox chemistry and transformation reactions of their radical cations and $\mathrm{e}^{-}$and $\mathrm{OH}$ adducts. Chem. Rev. 1989, 89, 503-520.

59. Steenken, S.; Telo, J. P.; Novais, H. M.; Candeias, L. P. One-electron-reduction potentials of pyrimidine bases, nucleosides, and nucleotides in aqueous solution. Consequences for DNA redox chemistry. J. Am. Chem. Soc. 1992; 114, 4701-4709.

60. Steenken, S.; Jovanovic, S. V. How easily oxidizable is DNA? One-electron reduction potentials of adenosine and guanosine radicals in aqueous solution. J. Am. Chem. Soc. 1997, 119, 617-618.

61. Steenken, S. Electron transfer in DNA? Competition by ultra-fast proton transfer? Biol. Chem. 1997, 378, 1293-1297.

62. Jang, Y. H.; GoddardIII, W. A.; Noyes, K. T.; Sowers, L. C.; Hwang, S.; Chung, D. S. First principles calculations of the tautomers and $\mathrm{p} K$ a values of 8-oxoguanine: Implications for mutagenicity and repair. Chem. Res. Toxicol. 2002, 15, 1023-1035.

63. Baik, M.-H.; Silverman, J. S.; Yang, I. V.; Ropp, P. A.; Szalai, V. A.; Yang, W.; Thorp, H. H. Using density functional theory to design DNA base analogues with low oxidation potentials. J. Phys. Chem. B 2001, 105, 6437-6444. 
64. Chen, X.; Syrstad, E. A.; Nguyen, M. T.; Gerbaux, P.; Tureček, F. Distonic isomers and tautomers of the adenine cation radical in the gas phase and aqueous solution. J. Phys. Chem. A 2004, 108, 9283-9293.

65. Adhikary, A.; Kumar, A.; Khanduri, D.; Sevilla, M. D. Effect of base stacking on the acid-base properties of the adenine cation radical $\left[\mathrm{A}^{\cdot+}\right]$ in solution: ESR and DFT studies. J. Am. Chem. Soc. 2008, 130, 10282-10292.

66. Nir, E.; Kleinermanns, K.; de Vries, M. S. Pairing of isolated nucleic-acid bases in the absence of the DNA backbone. Nature 2000, 408, 949-951.

67. Desfrançois, C.; Periquet, V.; Bouteiller, Y.; Schermann, J. P. Valence and dipole binding of electrons to uracil. J. Phys. Chem. A 1998, 102, 1274-1278.

68. Puiatti, M.; Vera, D. M. A.; Pierini, A. B. Species with negative electron affinity and standard DFT methods. Finding the valence anions. Phys. Chem. Chem. Phys. 2008, 10, 1394-1399.

69. Vera, D. M. A.; Pierini, A. B. Species with negative electron affinity and standard DFT methods. Phys. Chem. Chem. Phys. 2004, 6, 2899-2903.

70. Li, X. F.; Cai, Z. L.; Sevilla, M. D. DFT Calculations of the electron affinities of nucleic acid bases: Dealing with negative electron affinities. J. Phys. Chem. A 2002, 106, 1596-1603.

71. Wesolowski, S. S.; Leininger, M. L.; Pentchev, P. N.; Schaefer, H. F. Electron affinities of the DNA and RNA bases. J. Am. Chem. Soc. 2001, 123, 4023-4028.

72. Svozil, D.; Jungwirth, P.; Havlas, Z. Electron binding to nucleic acid bases. Experimental and theoretical studies. A review. Collect. Czech. Chem. Commun. 2004, 69, 1395-1428.

73. Bachorz, A. R.; Klopper, W.; Gutowski, M. Coupled-cluster and explicitly correlated perturbation-theory calculations of the uracil anion. J. Chem. Phys. 2007, 126, 085101.

74. Aflatooni, K.; Gallup, G. A.; Burrow, P. D. Electron attachment energies of the DNA bases. J. Phys. Chem. A 1998, 102, 6205-6207.

75. Desfrançois, C.; Carles, S.; Schermann, J. P. Weakly bound clusters of biological interest. Chem. Rev. 2000, 100, 3943-3962.

76. Hendricks, J. H.; Lyapustina, S. A.; de Clercq, H. L.; Snodgrass, J. T.; Bowen, K. H.; Dipole bound, nucleic acid base anions studied via negative ion photoelectron spectroscopy. J. Chem. Phys. 1996, 104, 7788-7791.

77. Hendricks, J. H.; Lyapustina, S. A.; de Clercq, H. L.; Snodgrass, J. T.; Bowen, K. H. The dipole bound-to-covalent anion transformation in uracil. J. Chem. Phys. 1998, 108, 8-11.

78. Schiedt, J.; Weinkauf, R.; Neumark, D. M.; Schlag, E. W. Anion spectroscopy of uracil, thymine and the amino-oxo and amino-hydroxy tautomers of cytosine and their water clusters. Chem. Phys. 1998, 239, 511-524.

79. Periquet, V.; Moreau, A.; Carles, S.; Schermann, J. P.; Desfrançois, C. Cluster size effects upon anion solvation of $\mathrm{N}$-heterocyclic molecules and nucleic acid bases. J. Electron Spectrosc. Relat. Phenom. 2000, 106, 141-151.

80. Wang, W.; Yan, M.; Becker, D.; Sevilla, M. D. The influence of hydration on the absolute yields of primary free radicals in gamma-irradiated DNA at $77 \mathrm{~K}$. II. Individual radical yields. Radiat. Res. 1993, 137, 2-10.

81. Wang, W.; Sevilla, M. D. Protonation of nucleobase anions in gamma-irradiated DNA and model systems. Which DNA base is the ultimate sink for the electron? Radiat. Res. 1994, $138,9-17$. 
82. Haranczyk, M.; Gutowski, M. Valence and dipole-bound anions of the most stable tautomers of guanine. J. Am. Chem. Soc. 2005, 127, 699-706.

83. Li, X. F.; Sevilla, M. D.; Sanche, L. Hydrogen atom loss in pyrimidine DNA bases induced by low-energy electrons: Energetics predicted by theory. J. Phys. Chem. B 2004, 108, 19013-19019.

84. Svozil, D.; Frigato, T.; Havlas, Z.; Jungwirth, P. Ab initio electronic structure of thymine anions. Phys. Chem. Chem. Phys. 2005, 7, 840-845.

85. Radisic, D.; Bowen, K. H.; Dabkowska, I.; Storoniak, P.; Rak, J.; Gutowski, M. AT base pair anions versus (9-Methyl-A)(1-Methyl-T) base pair anions. J. Am. Chem. Soc. 2005, 127, 6443-6450.

86. Richardson, N. A.; Wesolowski, S. S.; Schaefer, H. F. The adenine-thymine base pair radical anion: Adding an electron results in a major structural change. J. Phys. Chem. B 2003, 107, 848-853.

87. Gu, J. D.; Xie, Y. M.; Schaefer, H. F. Structural and energetic characterization of a DNA nucleoside pair and its anion: Deoxyriboadenosine (dA)-deoxyribothymidine (dT). J. Phys. Chem. B 2005, 109, 13067-13075.

88. Kumar, A.; Knapp-Mohammady, M.; Mishra, P. C.; Suhai, S. A theoretical study of structures and electron affinities of radical anions of guanine-cytosine, adenine-thymine, and hypoxanthine-cytosine base pairs. J. Comput. Chem. 2004, 25, 1047-1059.

89. Gu, J. A.; Xie, Y. M.; Schaefer, H. F. Electron attachment to nucleotides in aqueous solution. Chem. Phys. Chem. 2006, 7, 1885-1887.

90. Kim, S.; Wheeler, S. E.; Schaefer, H. F. Microsolvation effects on the electron capturing ability of thymine: Thymine-water clusters. J. Chem. Phys. 2006, 124, 204310.

91. Kim, S.; Schaefer, H. F. Effects of microsolvation on uracil and its radical anion: Uracil ${ }^{\bullet}$ $\left(\mathrm{H}_{2} \mathrm{O}\right)_{n}(n=1-5)$. J. Chem. Phys. 2006, 125, 144305.

92. Kim, S.; Schaefer, H. F. Microhydration of cytosine and its radical anion: Cytosine $\left(\mathrm{H}_{2} \mathrm{O}\right)_{n}(n=1-5)$. J. Chem. Phys. 2007, 126, 064301.

93. Gu, J. A.; Xie, Y. M.; Schaefer, H. F. Understanding electron attachment to the DNA double helix: The thymidine monophosphate-adenine pair in the gas phase and aqueous solution. J. Phys. Chem. B 2006, 110, 19696-19703.

94. Harańczyk, M.; Gutowski, M. Finding adiabatically bound anions of guanine through a combinatorial computational approach. Angew. Chem. Int. Ed. 2005, 44, 6585-6588.

95. Bao, X. G.; Sun, H.; Wong, N. B.; Gu, J. D. Microsolvation effect, hydrogen-bonding pattern, and electron affinity of the uracil-water complexes $\mathrm{U}-\left(\mathrm{H}_{2} \mathrm{O}\right)_{n}(n=1,2,3)$. J. Phys. Chem. B 2006, 110, 5865-5874.

96. Bao, X. G.; Liang, G. M.; Wong, N. B.; Gu, J. Microsolvation pattern of the hydrated radical anion of uracil: $\mathrm{U}^{-}\left(\mathrm{H}_{2} \mathrm{O}\right)_{n}(n=3-5)$. J. Phys. Chem. A 2007, 111, 666-672.

97. Kumar, A.; Mishra, P. C.; Suhai, S. Adiabatic electron affinities of the polyhydrated adenine-thymine base pair: A density functional study. J. Phys. Chem. A 2005, 109, 3971-3979.

98. Kumar, A.; Sevilla, M. D.; Suhai, S. Microhydration of the guanine-cytosine (GC) base pair in the neutral and anionic radical states: A density functional study. J. Phys. Chem. B 2008, 112, 5189-5198. 
99. Li, Z. J.; Zheng, Y.; Cloutier, P.; Sanche, L.; Wagner, J. R. Low energy electron induced DNA damage: Effects of terminal phosphate and base moieties on the distribution of damage. J. Am. Chem. Soc. 2008, 130, 5612-5613.

100. Martin, F.; Burrow, P. D.; Cai, Z.; Cloutier, P.; Hunting, D.; Sanche, L. DNA strand breaks induced by $0-4 \mathrm{eV}$ electrons: The role of shape resonances. Phys. Rev. Lett. 2004, 93, 068101.

101. Ptasińska, S.; Denifl, S.; Gohlke, S.; Scheier, P.; Illenberger, E.; Märk, T. D. Decomposition of thymidine by low-energy electrons: Implications for the molecular mechanisms of single-strand breaks in DNA. Angew. Chem., Int. Ed. 2006, 45, 1893-1896.

102. Denifl, S.; Zappa, F.; Mauracher, A.; da Silva, F. F.; Bacher, A.; Echt, O.; Mark, T. D.; Bohme, D. K.; Scheier, P. Dissociative electron attachment to DNA bases near absolute zero temperature: Freezing dissociation intermediates. Chem. Phys. Chem. 2008, 9, 1387-1389.

103. Li, X.; Sanche, L.; Sevilla, M. D. Base release in nucleosides induced by low-energy electrons: A DFT study. Radiat. Res. 2006, 165, 721-729.

104. Li, X.; Sevilla, M. D.; Sanche, L. Density functional theory studies of electron interaction with DNA: Can zero eV electrons induce strand breaks? J. Am. Chem. Soc. 2003, 125, 13668-13669.

105. Li, X.; Sanche, L.; Sevilla, M. D. Low energy electron interactions with uracil: The energetics predicted by theory. J. Phys. Chem. B 2004, 108, 5472-5476.

106. Li, X.; Sevilla, M. D.; Sanche, L. DFT investigation of dehalogenation of adeninehalouracil base pairs upon low-energy electron attachment. J. Am. Chem. Soc. 2003, 125, 8916-8920.

107. Li, X.; Sanche, L.; Sevilla, M. D. Dehalogenation of 5-halouracils after low energy electron attachment: A density functional theory investigation. J. Phys. Chem. A 2002, $106,11248-11253$.

108. Simons, J. How do low-energy $(0.1-2 \mathrm{eV})$ electrons cause DNA-strand breaks? Acc. Chem. Res. 2006, 39, 772-779.

109. Berdys, J.; Anusiewicz, I.; Skurski, P.; Simons, J. Damage to model DNA fragments from very low-energy ( $<1 \mathrm{eV}$ ) electrons. J. Am. Chem. Soc. 2004, 126, 6441-6447.

110. Barrios, R.; Skurski, P. Simons, J. Mechanism for damage to DNA by low-energy electrons. J. Phys. Chem. B 2002, 106, 7991-7994.

111. Berdys, J.; Skurski, P.; Simons, J. Damage to model DNA fragments by $0.25-1.0 \mathrm{eV}$ electrons attached to a thymine $\pi^{*}$ orbital. J. Phys. Chem. B 2004, 108, 5800-5805.

112. Bao, X.; Wang, J.; Gu, J.; Leszczynski, J. DNA strand breaks induced by near-zeroelectronvolt electron attachment to pyrimidine nucleotides. Proc. Natl. Acad. Sci. USA 2006, 103, 5658-5663.

113. Gu, J.; Xie, Y.; Schaefer, H. F. Glycosidic bond cleavage of pyrimidine nucleosides by low-energy electrons: A theoretical rationale. J. Am. Chem. Soc. 2005, 127, 1053-1057.

114. Gu, J.; Wang, J.; Leszczynski, J. Electron attachment-induced DNA single strand breaks: $\mathrm{C}_{3^{\prime}}-\mathrm{O}_{3^{\prime}} \sigma$-bond breaking of pyrimidine nucleotides predominates. J. Am. Chem. Soc. 2006, 128, 9322-9323.

115. Kumar, A.; Sevilla, M. D. Low-energy electron attachment to $5^{\prime}$-thymidine monophosphate: Modeling single strand breaks through dissociative electron attachment. $J$. Phys. Chem. B 2007, 111, 5464-5474. 
116. Kumar, A.; Sevilla, M. D. The role of $\pi \sigma^{*}$ excited states in electron-induced DNA strand break formation: A time-dependent density functional theory study. J. Am. Chem. Soc. 2008, 130, 2130-2131.

117. Millen, A. L.; Archibald, L. A. B.; Hunter K. C., Wetmore, S. D. A Kinetic and hermodynamic study of the glycosidic bond cleavage in deoxyuridine. J. Phys. Chem. B 2007, 111, 3800-3812.

118. bo Zhang, R.; Zhang, K.; Eriksson, L. A. Theoretical studies of damage to $3^{\prime}$ uridine monophosphate induced by electron attachment. Chem. Eur. J. 2008, 14, 2850-2856.

119. Schyman, P.; Eriksson, L. A.; bo Zhang, R.; Laaksonen, A. Hydroxyl radical-thymine adduct induced DNA damages. Chem. Phys. Lett. 2008, 458, 186-189.

120. Xie, H.; Wu, R.; Xia, F.; Cao, Z. Effects of electron attachment on $\mathrm{C}_{5^{\prime}}-\mathrm{O}_{5^{\prime}}$ and $\mathrm{C}_{1^{\prime}}-\mathrm{N}_{1^{\prime}}$ bond cleavages of pyrimidine nucleotides: A theoretical study. J. Comput. Chem. 2008, 29, 2025-2032.

121. Liang, G.; Bao, X.; Gu, J. The possibility of the decomposition of $2^{\prime}$-deoxyribose moiety of thymidine induced by the low energy electron attachment. J. Compu. Chem. 2008, 29, 2648-2655.

122. Caron, L.; Sanche, L. Diffraction in resonant electron scattering from helical macromolecules: Effects of the DNA backbone. Phys. Rev. A 2005, 72, 032726.

123. Caron, L.; Sanche, L. Temporary electron localization and scattering in disordered single strands of DNA. Phys. Rev. A 2006, 73, 062707.

124. Caron, L.; Sanche, L. Diffraction in resonant electron scattering from helical macromolecules: A- and B-type DNA. Phys. Rev. A 2004, 70, 032719.

125. Caron, L.; Sanche, L. Low-energy electron diffraction and resonances in DNA and other helical macromolecules. Phys. Rev. Lett. 2003, 91, 113201.

126. Caron, L.; Sanche, L. Adapting gas-phase electron scattering $R$-matrix calculations to a condensed-matter environment. Phys. Rev. A 2007, 76, 032716.

127. von Sonntag C. The Chemical Basis of Radiation Biology; Taylor and Francis, London, New York, Philadelphia, 1987, pp. 262-265.

128. Domcke, W.; Sobolewski, A. L. Chemistry-Unraveling the molecular mechanisms of photoacidity. Science 2003, 302, 1693-1694.

129. Sobolewski, A. L.; Domcke, W. On the mechanism of nonradiative decay of DNA bases: $\mathrm{Ab}$ initio and TDDFT results for the excited states of $9 \mathrm{H}$-adenine. Eur. Phys. J., D 2002, 20, 369-374.

130. Ashfold, M. N. R.; Cronin, B.; Devine, A. L.; Dixon, R. N.; Nix, G. D. The role of pi sigma* excited states in the photodissociation of heteroaromatic molecules. Science 2006, 312, 1637-1640.

131. Burrow, P. D.; Gallup, G. A.; Modelli, A. Are there $\pi^{*}$ shape resonances in electron scattering from phosphate groups? J. Phys. Chem. A 2008, 112, 41064113.

132. Becker, D.; Razskazovskii, Y.; Callaghan, M. U.; Sevilla, M. D. Electron spin resonance of DNA irradiated with a heavy-ion beam $\left({ }^{16} \mathrm{O}^{8+}\right)$ : Evidence for damage to the deoxyribose phosphate backbone. Radiat. Res. 1996, 146, 361-368.

133. Kim, J.; Kreller, C. R.; Greenberg, M. M. Preparation and analysis of oligonucleotides containing the $\mathrm{C} 4^{\prime}$-oxidized abasic site and related mechanistic probes. J. Org. Chem. 2005, 70, 8122-8129. 
134. Tronche, C.; Goodman, B. K.; Greenberg, M. M. DNA damage induced via independent generation of the radical resulting from formal hydrogen atom abstraction from the $\mathrm{Cl}^{\prime}$ position of a nucleotide. Chem. Biol. 1998, 5, 263-271.

135. Dedon, P. C. The chemical toxicology of 2-deoxyribose oxidation in DNA. Chem. Res. Toxicol. 2008, 21, 206-219.

136. Pogozelski, W. K.; Tullius, T. D. Oxidative strand scission of nucleic acids: Routes initiated by hydrogen abstraction from the sugar moiety. Chem. Rev. 1998, 98, 1089-1107.

137. Adhikary, A.; Collins, S.; Khanduri, D.; Sevilla, M. D. Sugar radicals formed by photoexcitation of guanine cation radical in oligonucleotides. J. Phys. Chem. B 2007, $111,7415-7421$.

138. Khanduri, D.; Collins, S.; Kumar, A.; Adhikary, A.; Sevilla, M. D. Formation of sugar radicals in RNA model systems and oligomers via excitation of guanine cation radical. J. Phys. Chem. B 2008, 112, 2168-2178.

139. Kumar, A.; Sevilla, M. D. Photoexcitation of dinucleoside radical cations: A timedependent density functional study. J. Phys. Chem. B 2006, 110, 24181-24188.

140. Blancafort, L.; Voityuk, A. A. CASSCF/CAS-PT2 study of hole transfer in stacked DNA nucleobases. J. Phys. Chem. A 2006, 110, 6426-6432.

141. Dreuw, A.; Weisman, J. L.; Head-Gordon, M. Long-range charge-transfer excited states in time-dependent density functional theory require non-local exchange. J. Chem. Phys. 2003, 119, 2943-2946.

142. Willson, R. L.; Wardman, P.; Asmus, K-D. Interaction of dGMP radical with cysteamine and promethazine as possible model of DNA repair. Nature (London) 1974, 252, 323-324.

143. Asmus, K.-D.; Deeble, D. J.; Garner, A.; Ali, K. M. I; Scholes, G. Chemical aspects of radiosensitization. Reaction of sensitizers with radicals produced in the radiolysis of aqueous solutions of nucleic acid components. Br. J. Cancer 1978, 37 (Suppl. III), $46-49$.

144. Candeias, L. P.; Steenken, S. Structure and acid-base properties of one-electron-oxidized deoxyguanosine, guanosine, and 1-methylguanosine. J. Am. Chem. Soc. 1989 111, 1094-1099.

145. Steenken, S.; Jovanovic, S. V.; Candeias, L. P.; Reynisson, Is "Frank" DNA-strand breakage via the guanine radical thermodynamically and sterically possible? J. Chem. Eur. J. 2001, 7, 2829-2833.

146. Kobayashi, K.; Tagawa, S. Direct observation of guanine radical cation deprotonation in duplex DNA using pulse radiolysis. J. Am. Chem. Soc. 2003, 125, 10213-10218.

147. Close, D. M.; Sagstuen, E.; Nelson, W. H. ESR study on the guanine cation. J. Chem. Phys. 1985, 82, 4386-4388.

148. Hole, E. O.; Sagstuen, E.; Nelson, W. H.; Close, D. M. Environmental effects on primary radical formation in guanine: Solid-state ESR and ENDOR of guanine hydrobromide monohydrate. Radiat. Res. 1991, 125, 119-128.

149. Jovanovic, S. V.; Simic, M. G. One-electron redox potentials of purines and pyrimidines. J. Phys. Chem. 1986, 90, 974-978.

150. Jovanovic, S. V.; Simic, M. G. The DNA guanyl radical: Kinetics and mechanisms of generation and repair. Biochim. Biophys. Acta. 1989, 1008, 39-44. 
151. Wetmore, S. D.; Boyd, R. J.; Eriksson, L. A. Comparison of experimental and calculated hyperfine coupling constants. Which radicals are formed in irradiated guanine? J. Phys. Chem. B 1998, 102, 9332-9343.

152. Mundy, C. J.; Colvin, M. E.; Quong, A. A. Irradiated guanine: A Car-Parrinello molecular dynamics study of dehydrogenation in the presence of an $\mathrm{OH}$ radical. J. Phys. Chem. A 2002, 106, 10063-10071.

153. Gervasio, F. L.; Laio, A.; Iannuzzi, M.; Parrinello, M. Influence of DNA structure on the reactivity of the guanine radical cation. Chem. Eur. J. 2004, 10, 4846-4852.

154. Luo, Q.; Li, Q. S.; Xie, Y.; Schaefer, H. F. Radicals derived from guanine: Structures and energetics. Collect. Czech. Chem. Commun. 2005, 70, 826-836.

155. Chatgilialoglu, C.; Caminal, C.; Guerra, M.; Mulazzani, Q. G. Tautomers of one-electronoxidized guanosine. Angew. Chem. Int. Ed. 2005, 44, 6030-6032.

156. Chatgilialoglu, C.; Caminal, C.; Altieri, A.; Vougiokalakis, G. C.; Mulazzani, Q. G.; Gimisis, T.; Guerra, M. Tautomerism in the guanyl radical. J. Am. Chem. Soc. 2006, 128, 13796-13805.

157. Adhikary, A.; Kumar, A.; Becker, D.; Sevilla, M. D. the guanine cation radical: investigation of deprotonation states by ESR and DFT. J. Phys. Chem. B 2006, 110, 24171-24180.

158. Naumov, S.; von Sonntag, C. Guanine-derived radicals: Dielectric constant-dependent stability and UV/Vis spectral properties: A DFT study. Radiat. Res. 2008, 169, 364-372.

159. Wagenknecht, H.-A.,Ed.; Charge Transfer in DNA: From Mechanism to Application; Wiley-VCH Verlag GmbH \& Co. KGaA, Weiheim, 2005, pp. 1-26.

160. Cai, Z.; Sevilla, M. D. Electron and hole transfer from DNA base radicals to oxidized products of guanine in DNA. Radiat. Res. 2003, 159, 411-419.

161. Colson, A.-O.; Besler, B.; Close, D. M.; Sevilla, M. D. Ab initio molecular-orbital calculations of DNA bases and their radical ions in various protonation states-Evidence for proton-transfer in GC base pair radical-anions. J. Phys. Chem. 1992, 96, 661-668.

162. Bertran, J.; Oliva, A.; Rodriguez-Santiago, L.; Sodupe, M. Single versus double protontransfer reactions in Watson-Crick base pair radical cations. A theoretical study. J. Am. Chem. Soc. 1998, 120, 8159-8167.

163. Nelson, W. H.; Sagstuen, E.; Hole, E. O.; Close, D. M. Electron spin resonance and electron nuclear double resonance study of X-irradiated deoxyadenosine: Proton transfer behavior of primary ionic radicals. Radiat. Res. 1998, 149, 75-86.

164. Candeias, L. P.; Steenken, S. Electron transfer in di(deoxy)nucleoside phosphates in aqueous solution: Rapid migration of oxidative damage (via adenine) to guanine. J. Am. Chem. Soc. 1993, 115, 2437-2440.

165. Giese, B.; Amaudrut, J.; Köhler, A.- K.; Spormann, M.; Wessely, S. Direct observation of hole transfer through DNA by hopping between adenine bases and by tunneling. Nature 2001, 412, 318-320.

166. Kawai, K.; Majima, T. In Charge Transfer in DNA: From Mechanism to Application; Wagenknecht, H.-A.,Ed.; Wiley-VCH Verlag GmbH \& Co. KGaA, Weiheim, 2005, pp. 117-151.

167. Lewis, F. D.; Daublain, P.; Zhang, L.; Cohen, B.; Vura-Weis, J.; Wasielewski, M. R.; Shafirovich, V.; Wang, Q.; Raytchev, M.; Fiebig, T. Reversible bridge-mediated excitedstate symmetry breaking in stilbene-linked DNA dumbbells. J. Phys. Chem. B. 2008, 112, 3838-3843. 
168. Augustyn, K. E.; Genereux, J. C.; Barton, J. K. Distance-Independent DNA Charge Transport across an Adenine Tract. Angew. Chem., Int. Ed. 2007, 46, 5731-5733.

169. Shao, F.; O’Neill, M. A.; Barton, J. K. Long-range oxidative damage to cytosines in duplex DNA. Proc. Natl. Acad. Sci. U. S.A. 2004, 101, 17914-17919.

170. Ts'o, P. O. P. In Fine Structure of Proteins and Nucleic Acids; Fasman, G. D.; Tiemasheff, S. N.,Eds.; Marcel Dekker, New York, 1970, p. 151.

171. Broom, A. D.; Schweizer, M. P.; Ts'o, P. O. P. Interaction and association of bases and nucleosides in aqueous solutions. V. Studies of the association of purine nucleosides by vapor pressure osmometry and by proton magnetic resonance. J. Am. Chem. Soc. 1967, $89,612-3622$.

172. Olsthoorn, C. S. M.; Bostelaar, L. J.; De Rooij, J. F. M.; Van Boom, J. H.; Altona, C. Circular dichroism study of stacking properties of oligodeoxyadenylates and polydeoxyadenylate. A three-state conformational model. Eur. J. Biochem. 1981, 115, 309-321.

173. Itahara, T.; Imaizumi, K. Role of nitrogen atom in aromatic stacking J. Phys. Chem. B 2007, 111, 2025-2032.

174. Leonard, N. J. Trimethylene bridges as synthetic spacers for the detection of intramolecular interactions. Acc. Chem. Res. 1979, 12, 423-429.

175. Cohen, A. J.; Mori-Sánchez, P.; Yang, W. Insights into current limitations of density functional theory. Science 2008, 321, 792-794. 